\title{
Chlorinated ethene plume evolution after source thermal remediation Determination of degradation rates and mechanisms
}

Murray, Alexandra Marie; Ottosen, Cecilie Bang; Maillard, Julien; Holliger, Christof; Johansen, Anders; Brabæk, Lærke; Kristensen, Inge Lise; Zimmermann, Jeremy; Hunkeler, Daniel; Broholm, Mette Martina

Published in:

Journal of Contaminant Hydrology

Link to article, DOI:

10.1016/j.jconhyd.2019.103551

Publication date:

2019

Document Version

Peer reviewed version

Link back to DTU Orbit

Citation (APA):

Murray, A. M., Ottosen, C. B., Maillard, J., Holliger, C., Johansen, A., Brabæk, L., Kristensen, I. L., Zimmermann, J., Hunkeler, D., \& Broholm, M. M. (2019). Chlorinated ethene plume evolution after source thermal remediation: Determination of degradation rates and mechanisms. Journal of Contaminant Hydrology, 227, [103551]. https://doi.org/10.1016/j.jconhyd.2019.103551

\section{General rights}

Copyright and moral rights for the publications made accessible in the public portal are retained by the authors and/or other copyright owners and it is a condition of accessing publications that users recognise and abide by the legal requirements associated with these rights.

- Users may download and print one copy of any publication from the public portal for the purpose of private study or research.

- You may not further distribute the material or use it for any profit-making activity or commercial gain

- You may freely distribute the URL identifying the publication in the public portal 
1 Chlorinated ethene plume evolution after source thermal remediation: determination of

2 degradation rates and mechanisms

3 Alexandra Marie Murray ${ }^{\mathrm{a}^{*}}$, Cecilie B. Ottosen ${ }^{\mathrm{a}}$, Julien Maillard ${ }^{\mathrm{b}}$, Christof Holliger ${ }^{\mathrm{b}}$, Anders

4 Johansen ${ }^{\mathrm{c}}$, Lærke Brabæk ${ }^{\mathrm{a}}$, Inge Lise Kristensen ${ }^{\mathrm{a}}$, Jeremy Zimmermann ${ }^{\mathrm{d}}$, Daniel Hunkeler ${ }^{\mathrm{d}}$, and

5 Mette M. Broholm ${ }^{\mathrm{a}}$

$6 \quad{ }^{a}$ Department of Environmental Engineering, Technical University of Denmark, Kgs. Lyngby, DK-

$7 \quad 2800$, Denmark

8 bLaboratory for Environmental Biotechnology, ENAC-IIE, Ecole Polytechnique Fédérale de

9 Lausanne, 1015 Lausanne, Switzerland

10 'Department of Environmental Science, Aarhus University, Frederiksborgvej 399, 4000 Roskilde,

11 Denmark

12 dUniversity of Neuchatel, Centre for Hydrogeology \& Geothermics (CHYN), Rue Emile Argand

13 11, CH 2000 Neuchatel, Switzerland

$14{ }^{*}$ Corresponding author and address:

15 Alexandra Marie Murray

16 Department of Environmental Engineering,

17 Technical University of Denmark

18 Bld 115, 2800 Lyngby

19 Denmark

20 E-mail address: almu@env.dtu.dk, Tel.: +45 45252174 
- 11-year study of monitored natural attenuation in a $2 \mathrm{~km}$ PCE plume

- In-situ chlorinated ethene degradation rates calculated over time and distance multiple lines of evidence

- Dual C-Cl isotope development through time and field-based enrichment factors

- Community sequencing and Dehalococcoides and Dehalogenimonas spp. quantification

- Biotic and abiotic cDCE reductive dechlorination mechanisms

\section{Key words}

Stable isotopes, molecular biology, Dehalogenimonas spp., biodegradation, abiotic degradation,

\section{Abstract}

The extent, mechanism(s), and rate of chlorinated ethene degradation in a large tetrachloroethene (PCE) plume were investigated in an extensive sampling campaign. Multiple lines of evidence for this degradation were explored, including compound-specific isotope analysis (CSIA), dual C-Cl isotope analysis, and quantitative real-time polymerase chain reaction (qPCR) analysis targeting the genera Dehalococcoides and Dehalogenimonas and the genes vcrA, bvcA, and cerA. A decade prior to this sampling campaign, the plume source was thermally remediated by steam injection. This released dissolved organic carbon (DOC) that stimulated microbial activity and created reduced conditions within the plume. Based on an inclusive analysis of minor and major sampling campaigns since the initial site characterization, it was estimated that reduced conditions peaked four years after the remediation event. At the time of this study, 11 years after the remediation event, the redox conditions in the aquifer are returning to their original state. However, the DOC released from the remediated source zone matches levels measured three years prior and plume conditions are still suitable for biotic reductive dechlorination. Dehalococcoides spp., 
Dehalogenimonas spp., and $v c r A, b v c A$, and cerA reductive dehalogenase genes were detected close to the source, and suggest that complete, biotic PCE degradation occurs here. Further downgradient, qPCR analysis and enriched $\delta^{13} \mathrm{C}$ values for cis-dichloroethene (cDCE) suggest that cDCE is biodegraded in a sulfate-reducing zone in the plume. In the most downgradient portion of the plume, lower levels of specific degraders supported by dual C-Cl analysis indicate that the biodegradation occurs in combination with abiotic degradation. Additionally, 16S rRNA gene amplicon sequencing shows that organizational taxonomic units known to contain organohaliderespiring bacteria are relatively abundant throughout the plume. Hydraulic conductivity testing was also conducted, and local degradation rates for PCE and cDCE were determined at various locations throughout the plume. PCE degradation rates from sampling campaigns after the thermal remediation event ranged from 0.11-0.35 $\mathrm{yr}^{-1}$. PCE and cDCE degradation rates from the second to the third sampling campaigns range from $0.08-0.10 \mathrm{yr}^{-1}$ and $0.01-0.07 \mathrm{yr}^{-1}$, respectively. This is consistent with cDCE as the dominant daughter product in the majority of the plume and cDCE degradation as the time-limiting step. The extensive temporal and spatial analysis allowed for tracking the evolution of the plume and the lasting impact of the source remediation and illustrates that the multiple lines of evidence approach is essential to elucidate the primary degradation mechanisms in a plume of such size and complexity.

\section{Introduction}

Chlorinated ethenes such as tetrachloroethene (PCE) are toxic pollutants commonly found in groundwater. Because chlorinated ethenes can be transported with groundwater over long distances and deep into aquifers, remediation is challenging. Natural attenuation is preferred whenever possible, and other intensive methods, such as thermal remediation, are used to remove chlorinated ethenes in plume source zones where the concentration is highest (Friis et al., 2005). Thermal remediation by steam enhanced extraction releases dissolved organic carbon (DOC) from the soil 
and aquifer material. The released DOC promotes microbial activity downgradient from the remediation site and can stimulate chlorinated ethene degradation by organohalide-respiring bacteria (OHRB) without additional engineering intervention; e.g. via biostimulation or bioaugmentation (Badin et al., 2016; Friis et al., 2005).

Just like naturally occurring $\mathrm{SO}_{4}{ }^{2-}$ and $\mathrm{Fe}(\mathrm{III})$, chlorinated ethenes can serve as electron acceptors in the subsurface (Holliger et al., 1993). The use of PCE as an electron acceptor by OHRB sequentially yields trichloroethene (TCE), cis-dichloroethene (cDCE), vinyl chloride (VC), and ultimately the harmless ethene. More reduced conditions are needed as the chlorinated ethenes become further degraded, and it is not uncommon for degradation of these compounds to slow or halt partway through the sequence and cause accumulation of cDCE and potentially the daughter product VC (Bradley, 2000; Shani et al., 2013). Degradation of these contaminants is also dependent on the presence of electron donors, typically $\mathrm{H}_{2}$, and the presence of bacteria capable of chlorinated ethene degradation. OHRB represent various bacterial genera, such as Sulfurospirillum, Dehalobacter, Desulfitobacterium, and Desulfuromonas, but these OHRB can only facilitate degradation to cDCE (Hug et al., 2013). Until recently, only the genus Dehalococcoides was identified as capable of degrading $\mathrm{CDCE}$ and VC to ethene via the VC dehalogenases VcrA and BvcA (Löffler et al., 2013; Yargicoglu and Reddy, 2015), though it had been posited that other as yet unidentified bacteria may also possess the capability (Maphosa et al., 2010). Recently, the genus Dehalogenimonas was identified as capable of VC reduction to ethene via the VC dehalogenase CerA (Yang et al., 2017). This discovery has shifted the paradigm that complete biotic degradation of chlorinated ethenes is only possible when Dehalococcoides is a main player in a groundwater microbial community. Further, it is also possible for CDCE and VC to be degraded by microbial oxidation, including microaerophilic oxidation, cometabolic oxidation by methanotrophs and etheneotrophs, or anaerobic oxidation (Bradley et al., 1998; Bradley and Chapelle, 2000; Liang et 
al., 2017; Smits et al., 2011). Chlorinated ethene degradation may also proceed abiotically in ironand sulfate-reducing conditions when mediated by reactive iron minerals such as iron sulfides, magnetite, and green rust (He et al., 2015). For instance, the iron sulfide mineral pyrite is capable of degrading all chlorinated ethene compounds via $\beta$-elimination, where the main product is acetylene (Lee and Batchelor, 2002a).

It is recommended for risk management of monitored natural attenuation to assess the extent, mechanism, and rate of degradation of chlorinated ethenes in the subsurface (Yargicoglu and Reddy, 2015) in what can be called the multiple lines of evidence approach. In this approach, various analyses are used in combination to yield a comprehensive picture of the state of a contaminant plume (Wilson, 2010), and it has been used successfully over the past decade (Courbet et al., 2011; Damgaard et al., 2013; Imfeld et al., 2008; Nijenhuis et al., 2007). New chemical and biological tools are available that can aid in this endeavor. One such tool is compound specific isotopic analysis (CSIA), which has been used over the last decades to determine in situ degradation of chlorinated ethenes (Braeckevelt et al., 2012). Additionally, dual C-Cl analysis can assist in distinguishing between degradation pathways (Elsner et al., 2012). The database of laboratory determined C-Cl isotope slopes has continued to expand in recent years, though there are still limitations that render this method best used along with other lines of evidence (Badin et al., 2016; Doğan-Subaşı et al., 2017; Gafni et al., 2018). Bio-molecular approaches can also assist in assessing the likelihood that biotic degradation occurs. Quantitative real-time polymerase chain reaction

111 (qPCR) analyses can be used to identify whether specific genera and reductive dehalogenase $(r d h A)$ genes are present in the plume, and Illumina sequencing analysis can be used to screen the entire 113 microbial community (Imfeld et al., 2011; Paes et al., 2015; Yargicoglu and Reddy, 2015).

114 Moreover, when the mechanism and extent of degradation are quantified and combined with 115 knowledge of the aquifer hydrogeology, the rate of degradation can be estimated. This is essential 
116 knowledge for accurate risk assessment of a polluted site - yet few of the rates published in the

117 literature are determined at the field scale, and for chlorinated ethenes, published rates span multiple 118 orders of magnitude (Ottosen et al., 2019).

119 The aim of the current study is to use the new tools and knowledge available, including knowledge 120 about Dehalogenimonas spp. and dual C-Cl isotope analysis, to investigate the degradation 121 mechanism(s) that occur in a chlorinated ethene plume and to quantify the rate at which degradation 122 proceeds. Furthermore, we aim to assess the long-term impact of source thermal remediation on a 123 chlorinated ethene plume. Use of the multiple lines of evidence approach is essential because little 124 VC is measured in the plume, and thus the fate of cDCE is unclear (Damgaard et al., 2013). The new tools can in particular advance our understanding of the fate of cDCE.

126 Two previous comprehensive sampling campaigns have been conducted on the plume, one prior to 127 thermal remediation and one eight years later. The current study has been carried out 11 years post128 remediation. A comprehensive sampling campaign was conducted that involved measurement of 129 hydraulic conductivity, redox parameters, and chlorinated ethene concentrations and isotopic 130 composition; qPCR analysis of selected OHRB and VC $r d h A$ genes, including the newly reported 131 cerA; and bacterial community analysis by 16S rRNA gene amplicon sequencing. This extensive 132 characterization of the Rødekro plume, through time and with numerous lines of evidence, allows 133 for both localized and broad interpretation of the degradation mechanisms that occur throughout the 134 plume. In this study, we first present each line of evidence and its interpretation individually and 135 then discuss process understanding of each section of the plume based on review of all lines of 136 evidence. We conclude by evaluating the spatial and temporal evolution of the plume as a whole 137 and give some prospective remarks as to possible further development. 
139 The study site is located in the town of Rødekro, in southern Denmark, and has previously been 140 described by Hunkeler et al., 2011 and Badin et al., 2016. A dry-cleaning facility was in operation 141 at the site from 1964 to 2001, and is the origin of the PCE contamination. The subsurface material is 142 primarily sand, interspersed with gravel and clay lenses (Hunkeler et al., 2011). A PCE plume 143 originates from the decommissioned dry-cleaning facility and extends $\sim 2 \mathrm{~km}$ downgradient toward 144 the south; after $1 \mathrm{~km}$ the plume bends slightly toward the southeast, in accordance with the 145 flowfield depicted in Figure 1. 


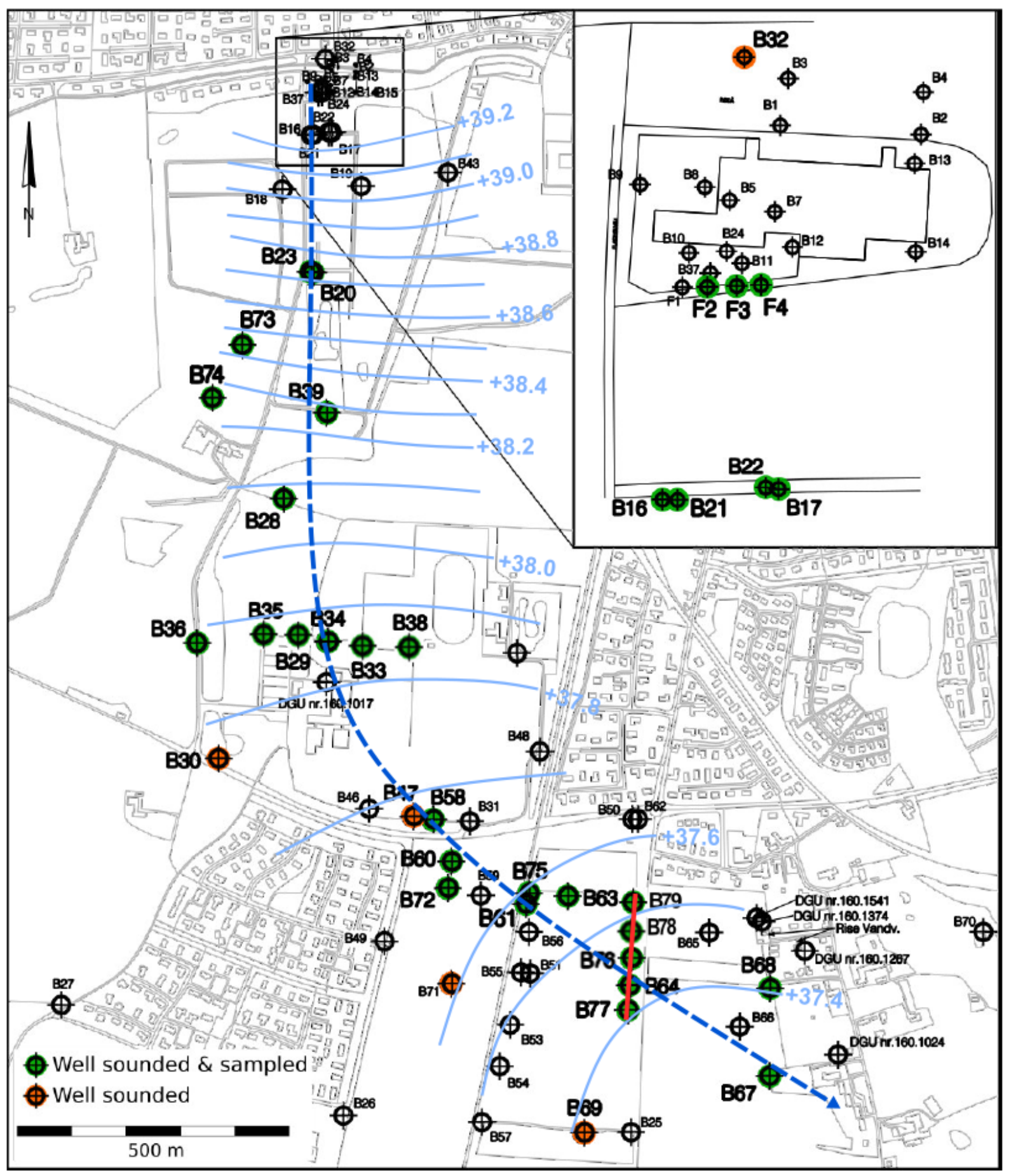

147 Figure 1: Sampling scheme for the 2017 sampling campaign, groundwater equipotential lines from 1482017 (light blue), and approximate plume flowline (dashed dark blue). All well locations indicated 149 with a color (both green and orange) were sounded; well locations indicated in green were also 150 sampled. Map insert shows the source zone and sampled wells (F2, F3, and F4) that are 
151 immediately downgradient from the source. Detailed information about which analyses were 152 conducted at each sampled location is included in Table S1.

153 Thermal remediation via steam injection was conducted at the source zone in 2006, which

154 effectively removed the main dense non-aqueous phase liquid source. The initial state of the plume 155 is presented in Hunkeler et al., 2011, and the effect of the thermal remediation event after eight 156 years, in 2014, is described by (Badin et al., 2016). Chlorinated ethene concentrations measured in 157 the plume from close to the source zone to $750 \mathrm{~m}$ from the source were $85 \%$ lower in 2014 than in 158 2006. A main impact of the source remediation event was a DOC release from the soil and aquifer 159 material, which stimulated microbial activity and reduced the redox conditions in the aquifer, such 160 that a zone 1050 to $1400 \mathrm{~m}$ from the source were suitable for reductive dechlorination of cDCE and 161 VC. It was determined from the first and second major sampling campaigns that PCE and TCE 162 underwent biotic degradation in the first $400 \mathrm{~m}$ of the plume before remediation and in the first $1631000 \mathrm{~m}$ of the plume after remediation. It was also determined that cDCE did not undergo 164 degradation in the first $1050 \mathrm{~m}$ from the source zone, before the remediation event, but eight years 165 later did undergo biotic degradation within $1000 \mathrm{~m}$ from the source zone. Degradation of cDCE and 166 VC in the plume was documented; it was not possible to ascertain the exact mechanism of cDCE 167 (and VC) degradation from $1400 \mathrm{~m}$ until the plume front, but in both 2006 and 2014, there is 168 evidence that a combination of reductive dechlorination and abiotic degradation was responsible.

169 Since 2014, five new wells have been drilled, these are B75, B76, B77, B78, and B79 (Figure 1). 170 Wells B76 through B79 are located directly north and south of well B64 and form a 100 m transect 171 across the plume near the front, at $1900 \mathrm{~m}$ from the source. Wells B36, B35, B29, B34, B33, and 172 B38 form another transect across the plume at $1050 \mathrm{~m}$ from the source. The flow line of the plume 173 was determined based on measurements taken in these transects, and it was determined that the 
flowline was the same as in the previous two studies. More information on the new transect can be found in the Supplementary Information.

\section{Materials and methods}

\subsection{Hydraulic testing: slug tests and pump tests}

Vacuum slug tests were conducted in duplicate on 25 screens in six boreholes (Table S2) during the 2017 field investigation. Pump tests were also conducted on nine of these screens in three boreholes. Data was collected using Slug Test Acquisition ${ }^{\circledR}$ software (Geoprobe Systems ${ }^{\circledR}$ ) and analyzed with AQTESOLV Pro ${ }^{\circledR}$ software (HydroSOLVE, Inc.); the Springer-Gelhar and Kansas Geological Survey models were used to interpret the slug test data and determine the hydraulic conductivity for the sandy, underdamped and clayey, overdamped portions of the Rødekro aquifer, respectively. Pump test data were analyzed with the Theis solution (Theis, 1935).

\subsection{Groundwater sampling}

In the 2017 sampling campaign, which spanned four weeks in March-April, 52 screens from 24 boreholes were sampled (Figure 1, Table S1). Boreholes not on the flowline that formed the two transects were sampled at a later date (Figure 1, Table S1). Sampled boreholes are indicated in green in Figure 1. An additional nine boreholes were sounded during the campaign, indicated in orange in Figure 1. Sampling procedures were the same as those used in the previous two campaigns (Badin et al., 2016; Hunkeler et al., 2011) except for the following minor differences. Sampling materials for nitrate $\left(\mathrm{NO}_{3}{ }^{-}\right)$, sulfate $\left(\mathrm{SO}_{4}{ }^{2-}\right)$, ferrous iron (Fe(II)), manganese $\left(\mathrm{Mn}^{2+}\right)$, and methane $\left(\mathrm{CH}_{4}\right)$ were provided by Eurofins (Eurofins Miljø A/S, Denmark). Samples for chlorinated ethene isotope analysis were acidified with $\mathrm{HCl} ; 40 \mathrm{~mL}$ samples were collected in quadruplicate, and $1 \mathrm{~L}$ samples were collected in duplicate. Samples for analysis by Microbial Insights were taken with Sterivex $^{\mathrm{TM}}$ filters and fastenings provided by Microbial Insights, Inc. (Knoxville, TN, USA) and were stored in $50 \mathrm{~mL}$ Falcon tubes at $-10{ }^{\circ} \mathrm{C}$ until shipment to Microbial Insights (Microbial 
Insights Europe, Wondelgem, Belgium) for analysis. Samples for 16S rRNA amplicon sequencing and $r d h A$ analysis were collected by passing $0.93-3 \mathrm{~L}$ of groundwater through a $0.22 \mu \mathrm{m}$ Sterivex ${ }^{\mathrm{TM}}$ filter (Millipore Corporation Billerica, MA, USA) via vacuum pump and were flash frozen in the field in liquid $\mathrm{N}_{2}$. Samples were stored at $-80^{\circ} \mathrm{C}$ before analysis at Aarhus University (AU) in Roskilde, Denmark or shipment on dry ice to Ecole Polytechnique Fédérale de Lausanne (EPFL) in Switzerland. Samples for rRNA analysis were collected by passing 4-5 L of groundwater through a $0.2 \mu \mathrm{m}$ MicroFunnel $^{\mathrm{TM}}$ filter (Pall Corporation, Port Washington, NY, USA) via vacuum pump, stored in a CryoTube (Nunc A/S, Roskilde, Denmark), and were flash frozen in the field in liquid $\mathrm{N}_{2}$ and stored at $-80{ }^{\circ} \mathrm{C}$ before analysis at AU in Roskilde, Denmark.

\subsection{Analyses}

\subsubsection{Chemical analysis}

All sampled well screens were analyzed for aqueous redox relevant chemical parameters as well as for PCE and its degradation products. Of these, 37 well screens were also analyzed for the gases methane, ethene, ethane, and acetylene (Figure 1, Table S1). Analyses for aqueous $\mathrm{NO}_{3}{ }^{-}, \mathrm{Mn}^{2+}$, $\mathrm{Fe}(\mathrm{II}), \mathrm{SO}_{4}{ }^{2-}$, and DOC were conducted by the accredited (DANAK, ISO/IEC 17025) laboratory Eurofins in Veen, Denmark (Package AAG, Eurofins Miljø A/S, Denmark) with detection limits of $0.3 \mathrm{mg} \mathrm{L}^{-1}, 0.005 \mathrm{mg} \mathrm{L}^{-1}, 0.01 \mathrm{mg} \mathrm{L}^{-1}, 0.5 \mathrm{mg} \mathrm{L}^{-1}$, and $0.1 \mathrm{mg} \mathrm{L}^{-1}$ respectively. PCE, TCE, cDCE, and VC were also analyzed by Eurofins with a gas chromatography-mass spectrometer (GC-MS) and a detection limit of $0.02 \mu \mathrm{g} \mathrm{L}^{-1}$ for all compounds. Methane, ethene, ethane, and acetylene were measured at the Technical University of Denmark (DTU, Kongens Lyngby, Denmark) using a headspace gas chromatograph with a flame ionization detector (GC-FID) (Thermo Scientific TRACE 1300 GC with HP-plot Q capillary column 8 m x 0.32 mm / I.D. 0.02 mm, Agilent Technologies). The detection limit was $0.05 \mu \mathrm{g} \mathrm{L}^{-1}$ for methane and $0.25 \mu \mathrm{g} \mathrm{L}^{-1}$ for ethene, ethane, and acetylene and the results were processed with Chromeleon software (Thermo Scientific). 


\subsubsection{Isotopic analysis}

223 Samples from 37 well screens (Table S1) were collected for compound specific isotope analysis 224 (CSIA) for carbon and chlorine. Carbon isotope ratios $\left({ }^{13} \mathrm{C} /{ }^{12} \mathrm{C}\right)$ were measured with an isotope ratio mass spectrometer coupled to a gas chromatograph by a combustion interface (GC-C-IRMS) at the University of Neuchâtel (CHYN, Switzerland) using the method described by (Badin et al., 2016) with detection limits of $30 \mu g \mathrm{~L}^{-1}, 30 \mu \mathrm{g} \mathrm{L}^{-1}, 25 \mu \mathrm{g} \mathrm{L}{ }^{-1}$, and $7 \mu \mathrm{g} \mathrm{L} \mathrm{L}^{-1}$ for PCE, TCE, cDCE, and VC, respectively. Sets of Vienna Pee Dee Belemnite (VPDB) referenced standards of PCE, TCE, and cDCE were prepared and analyzed in the same manner as the samples to correct for isotope fractionation which may occur during sample preparation and analysis. A purge and trap system was applied, with a purge volume of $25 \mathrm{~mL}$. For samples with chlorinated ethene concentrations lower than these detection limits, a purge volume of $1 \mathrm{~L}$ was applied (Badin et al., 2016), and detection limits for carbon isotope fractionation were $1.3 \mu \mathrm{g} \mathrm{L}{ }^{-1}, 1.1 \mu \mathrm{g} \mathrm{L}-1,0.8 \mu \mathrm{g} \mathrm{L}^{-1}$, $0.6 \mu \mathrm{g} \mathrm{L}^{-1}$ for PCE, TCE, cDCE, and VC, respectively. Chlorine isotope ratios $\left({ }^{37} \mathrm{Cl} /{ }^{35} \mathrm{Cl}\right)$ were also measured as previously described by Badin et al., 2016 for PCE and TCE, with minimum required

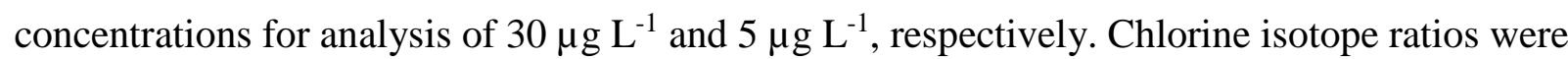
obtained by measuring pairs of ion fragments using a quadrupole mass spectrometer following separation with a gas chromatograph. During each measuring sequence the samples were bracketed with two external standards referenced to the Standard Mean Ocean Chloride (SMOC) in order to allow reporting of sample isotope ratios relative to SMOC using a two-point calibration.

\subsubsection{Molecular biology analysis}

242 Six samples from wells along the centerline of the plume (F3, F4, B23, B34, B58, B61) and one 243 sample from the outer fringe of the plume (B75-1) were sent to Microbial Insights (Microbial 244 Insights Europe, Wondelgem, Belgium) for QuantArray®-Chlor analysis, which includes 245 quantitative polymerase chain reaction (qPCR) for multiple organohalide-respiring genera 
(Dehalococcoides, Dehalobacter, Dehalogenimonas, Desulfitobacterium, Dehalobium, and

Desulfuromonas) and $r d h A$ genes (tceA, bvcA, vcrA, and the newly identified cerA, capable of degrading VC to ethene (Yang et al., 2017)).

DNA and rRNA extraction was conducted at AU for all other microbial samples. Sterivex ${ }^{\mathrm{TM}}$ filters were opened up, and both the Sterivex ${ }^{\mathrm{TM}}$ and MicroFunnel $^{\mathrm{TM}}$ filters were pulverized. DNA was then extracted, purified, and in some cases up-concentrated from the Sterivex ${ }^{\mathrm{TM}}$ filters and rRNA from the MicroFunnel ${ }^{\mathrm{TM}}$ filters. Analyses for the specific degrader genera Dehalococcoides and Dehalogenimonas were conducted via qPCR. Primer and thermocycling information is included in 254 the SI. Because there is only one 16S rRNA gene per Dehalococcoides genome, qPCR results of copies $\mathrm{L}^{-1}$ are equivalent to cells $\mathrm{L}^{-1}$ (Ritalahti et al., 2006). Sufficient genetic material was obtained from wells F2, F4, B16, B17, and B23 (Table S1) for specific degrader and gene qPCR analysis. Sufficient rRNA for activity analysis was collected from wells F4, B17, and B23 (Bead-Beat Total RNA kit, A\&A Biotechnology, Polen). Remaining DNA was removed (DNase I, RNase-free, 259 Thermo Fisher Scientific, US) and cDNA was produced using a High-Capacity cDNA Reverse 260 Transcription kit with RNase Inhibitor (Thermo Fisher Scientific, US). The cDNA was analyzed by qPCR for content of Dehalococcoides, bvcA, and vcrA (Bælum et al., 2013).

Eleven of the DNA samples extracted from the Sterivex ${ }^{\mathrm{TM}}$ filters were sent to EPFL for community analysis via 16S rRNA amplicon sequencing (F2, F4, B16, B17, B23, B34, B58, B61, and B64). DNA samples were amplified by PCR with adapter-containing primers LBE-AS-27F and LBE-AS338R with Q5 High-Fidelity polymerase (BioLabs) (see SI for primer and thermocycling 266 information). PCR products were first purified with Agencourt AMPure XP beads according to the 267 manufacturer's instructions and quantified with the Fragment Analyser (DNF-473 standard 268 sensitivity NGS fragment analysis kit, Advanced Analytical Technologies Inc., U.S.A). Addition of 12-nt barcodes, final sample preparation, and sequencing in paired-end mode (2x250bp) were 
performed by the Genomic Technologies Facility (GTF, University of Lausanne, Switzerland)

271 following the standard Illumina MiSeq protocol (Illumina, Inc., CA, USA). Analysis of the raw amplicon sequences was performed using a custom python bioinformatics pipeline developed at the Laboratory for Environmental Biotechnology at EPFL. First, the sequences were de-multiplexed and the barcodes were removed. Sequences were then trimmed with Timmomatic-0.36 and contigs formed with PEAR version 0.9.11 (Zhang et al., 2014). Clusters were created using CD-HIT-EST with $97 \%$ identity and $n=5$ and aligned using Infernal 1.1.2 (Nawrocki and Eddy, 2013) in order to remove non-16S rRNA sequences. The aligned clusters were blasted against the Greengenes database (McDonald et al., 2012) to attribute operational taxonomic units (OTUs) to the entire cluster using similarity thresholds of $75.0 \%$ for phylum, $78.5 \%$ for class, $82.0 \%$ for order, $86.5 \%$ for family, and $94.5 \%$ for genus (Yarza et al., 2014). OTUs were categorized by functional group as described in Badin et al., 2016; the category assignments are included in Table S5 in the Supplementary Information.

\subsection{Calculations}

\subsubsection{Pore water velocity and contaminant transport}

The pore water velocity was calculated for the locations where slug and pump tests were performed using the Darcy equation (Equation 1), and the distance a particle would move downgradient

287 without degradation or dispersion was calculated using Equation 2:

$$
\begin{aligned}
& v_{p, i}=\frac{K_{i} \cdot I}{\varphi} \\
& d_{i}=\frac{v_{p, i} \cdot t}{R}
\end{aligned}
$$
where $v_{p, i}\left[\mathrm{~m} \mathrm{~d}^{-1}\right]$ is the pore water velocity at location $i ; K_{i}\left[\mathrm{~m} \mathrm{~d}^{-1}\right]$ is the hydraulic conductivity at location $i ; I[-]$ is the hydraulic gradient; $\varphi[-]$ is the porosity; $d_{i}[\mathrm{~m}]$ is the distance the aqueous 
291 ] is the retardation factor, a ratio of the pore water velocity to the velocity of the aqueous species

292 (Nazaroff and Alvarez-Cohen, 2001) . $K_{i}$ was determined as described in Section 3.1. I was

293 calculated from the hydraulic potential map. Typical values for a Danish aquifer were selected for $294 \varphi, 0.35$ for sand and 0.5 for clay (Appelo \& Postma, 2005). The distance an aqueous species would 295 move downgradient was calculated piecewise, where the aquifer was divided into three discrete 296 flow zones, $i$, based on the location of clay lenses in the geology. These zones were from 0-700 m 297 from the source, 700-1200 $\mathrm{m}$ from the source, and $>1200 \mathrm{~m}$ from the source. Each flow zone was 298 attributed an average $K_{i}$ based on the slug test results. When calculating transport of the chlorinated 299 ethene contamination, a value of 1.2 was selected for $R$ for PCE and TCE based on values 300 determined empirically from chlorinated ethene transport in sand aquifers with low organic content 301 (Kret et al., 2015). Because the octanol-water partition coefficient for cDCE is nearly half that of PCE (Cwiertny and Scherer, 2010), $R$ for cDCE was assumed to be 1.

\subsubsection{Isotope balance, extent of degradation, and degradation rates}

304 Carbon isotope results are presented as a fraction of ${ }^{13} \mathrm{C} /{ }^{12} \mathrm{C}$ relative to the VPDB international 305 standard in delta notation, where $\delta=\left(\mathrm{R} / \mathrm{R}_{\text {std }}-1\right) * 1000$ [\%o] and $\mathrm{R}$ and $\mathrm{R}_{\text {std }}$ are the ratio of the heavy isotope to the light isotope in the sample and the standard, respectively (Hunkeler et al., 2011). Chloride isotopes are presented in the same manner as the ratio of ${ }^{37} \mathrm{Cl} /{ }^{35} \mathrm{Cl}$ relative to the SMOC international standard. In order to determine whether degradation to compounds which were not detected occurred to a significant degree, the $\delta^{13} \mathrm{C}$ balance was calculated as in Badin et al., 2016.

The extent of degradation and the degradation rates were calculated based on the $\delta^{13} \mathrm{C}$ values relative to the initial relative carbon isotope fraction, $\delta^{13} \mathrm{C}_{0}$, of the mother compound PCE, which was determined in (Hunkeler et al., 2011) to be -25 \%. When all of the mother compound has been converted to a daughter compound, that daughter compound can be treated as the mother compound 
for calculation of the degradation rate. The extent of degradation (D) as a fraction was calculated using Equation 3 (Badin et al., 2016):

$$
D=1-\exp \left(\frac{\Delta \delta^{13} C}{\varepsilon}\right)
$$

Where $\varepsilon\left[\%\right.$ ] is the enrichment factor. An enrichment factor for carbon, $\varepsilon_{C}$, of $-8.4 \%$ was found by using dual C-Cl plots (Section 4.4.1) and was applied to estimate the degradation extent of PCE. Literature values were applied for cDCE; due to uncertainty of the dominating degradation pathway, minimum and maximum enrichment values were found from literature ranges for both biotic and abiotic pathways. For biotic reductive dechlorination of $\mathrm{cDCE}$, the $\varepsilon_{\mathrm{C}}$ range is $-14.1 \%$ o to -31.1\%o (Bloom et al., 2000; Lihl et al., 2019). For abiotic dechlorination of cDCE, the $\varepsilon_{C}$ range is 6.9\%o to -21.7\%o (Elsner et al., 2008; Vanstone et al., 2004). The enrichment factors applied for estimating the extent of cDCE degradation were thus $-6.9 \%$ and $-31.1 \%$.

First order degradation rates for ${ }^{12} \mathrm{C}$ were calculated using Equation 4, modified from (Morrill et al., 2005) to include the retardation factor, $R$ :

$$
k_{C E, i}^{12}=\frac{-\left(\frac{1000}{\varepsilon}\right) \cdot \ln \left(\frac{\delta^{13} C / 1000+1}{\delta^{13} C_{0} / 1000+1}\right)}{R \cdot L / v_{p, i}}
$$

where $k_{C E, i}^{12}\left[\mathrm{~d}^{-1}\right]$ is the first order degradation rate for ${ }^{12} \mathrm{C}$ in chlorinated ethene $C E$ in location $i$, and $L[\mathrm{~m}]$ is the distance from the location where degradation began. For PCE this is the source, and for cDCE this is where $\delta^{13} \mathrm{C}_{\mathrm{CDCE}}=\delta^{13} \mathrm{C}_{0, \mathrm{PCE}}$. A degradation rate can also be calculated based on location rather than distance by replacing the denominator in Equation 4 with time between the measurements. Half-lives, $T_{1 / 2}$, were calculated by $\ln (2) / k_{C E, i}^{12}$.

\section{Results \& Discussion}

\subsection{Hydraulic conductivity and pore water velocity}


334 The hydraulic conductivity determined by the slug and pump tests generally agreed, though the 335 hydraulic conductivity measured by the pump tests was consistently one order of magnitude lower 336 than that measured by the slug tests. The hydraulic conductivity was determined to be $1.97 \times 10^{-3} \mathrm{~m}$ $337 \mathrm{~s}^{-1}\left(170 \mathrm{~m} \mathrm{~d}^{-1}\right)$ on average in the underdamped portions of the aquifer and $2.11 \times 10^{-4} \mathrm{~m} \mathrm{~s}^{-1}\left(18 \mathrm{~m} \mathrm{~d}^{-1}\right)$ 338 in the overdamped portions. Hydraulic conductivity data for both the slug and pump tests is 339 included Table S2 and Figure S2 in the Supplementary Information.

340 The pore water velocity along the central flow line decreases with distance from the source zone 341 (Figure 2). For the first $400 \mathrm{~m}$ downgradient from the source, a clay lens at 20 meters below ground 342 surface (mbgs) constricts the groundwater flow; when the lens is no longer present, the pore water 343 velocity slows down. By $1400 \mathrm{~m}$ from the source, the pore water velocity is approximately ten 344 times less than the velocity $400 \mathrm{~m}$ from the source, with local variations likely due to a few 345 significant clay lenses present in this portion of the aquifer. The pore water velocity from the source 346 zone to $700 \mathrm{~m}$ is approximately $300 \mathrm{~m} \mathrm{yr}^{-1}$ on average. In the transitional section from $700-1200$ $347 \mathrm{~m}$ from the source zone, where the plume is no longer confined by the clay lens at 20 mbgs and 348 expands in the vertical direction, the average pore water velocity is $200 \mathrm{~m} \mathrm{yr}^{-1}$. From $1200 \mathrm{~m}$ to the 349 plume front, the average pore water velocity is approximately $60 \mathrm{~m} \mathrm{yr}^{-1}$. Representative, rather than 350 average, pore water velocity values were chosen for each section. 


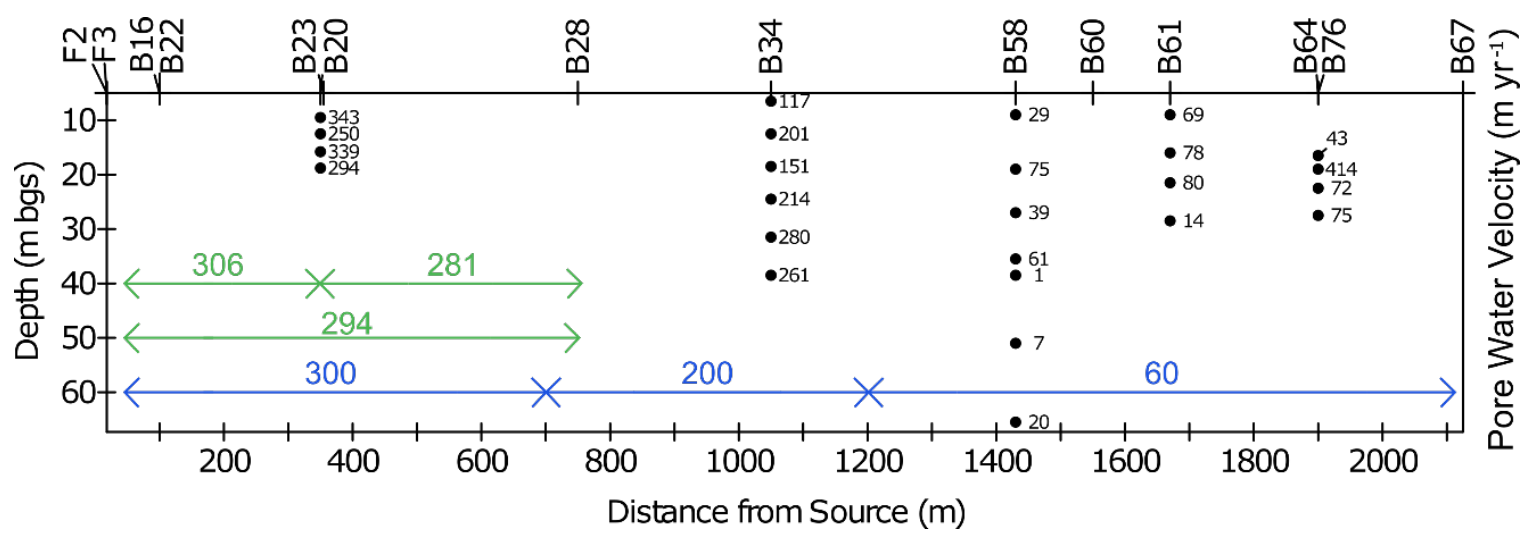

352 Figure 2: Pore water velocity along the approximate plume flowline, calculated using hydraulic 353 conductivity values determined via slug tests conducted in 2017. The arrows represent assumed 354 pore water velocities for specific distances to assess transport (blue) and for estimation of 355 degradation rates (green).

356 In 2006, the hydraulic conductivity of the aquifer, based on one pump test, was estimated to be $6.5 \times 10^{-4} \mathrm{~m} \mathrm{~s}^{-1}$, corresponding to a groundwater velocity of $0.24 \mathrm{~m} \mathrm{~d}^{-1}$ or $87 \mathrm{~m} \mathrm{yr}^{-1}$ with parameters typical for a sandy, Danish aquifer. It was estimated that from 2006 to 2014, chlorinated ethenes 359 could be expected to be transported $600 \mathrm{~m}$ downgradient without degradation. Using local pore 360 water velocities determined in 2017, the estimated transport of chlorinated ethenes between 20143612017 without degradation is as follows: PCE and TCE near the source zone would be transported 362 approximately 750 m downgradient; cDCE near the longitudinal center of the plume, near B34, 363 would be transported approximately $600 \mathrm{~m}$ downgradient; and cDCE in the last portion of the 364 plume, near wells B58 to B64, would be transported approximately 150 m downgradient.

\subsection{Redox conditions}

366 The redox conditions in and along the length of the plume are variable, and adds interest to the continued investigation of the plume. Interpreted redox profiles for all three sampling campaigns are depicted in Figure 3. Measured concentrations of individual redox sensitive species for the 2006 
and 2014 sampling campaigns have been published previously (Badin et al., 2016; Hunkeler et al.,

370 2011), and 2017 redox data for individual parameters are included in Figure S3 in the

371 Supplementary Information.

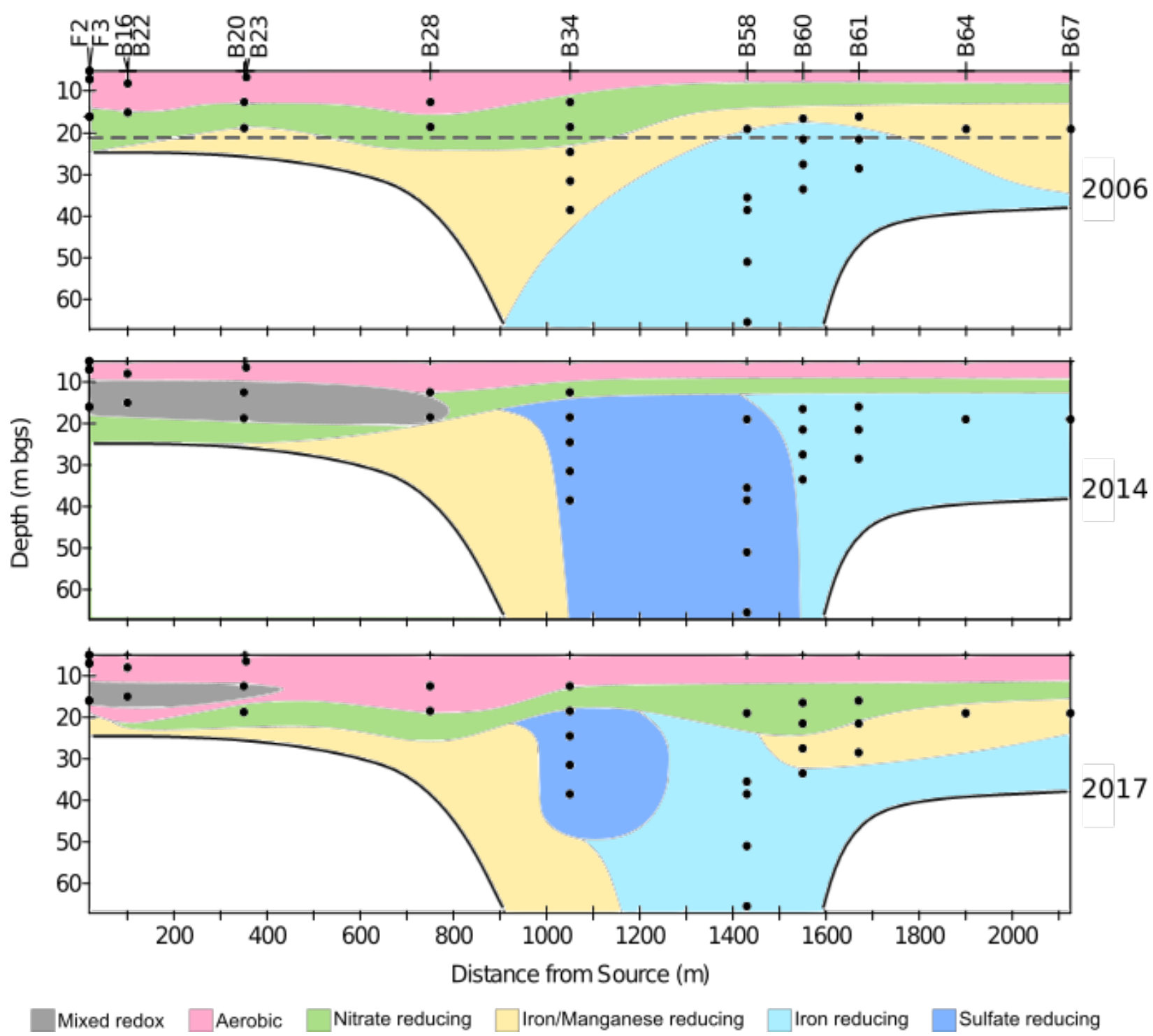

373 Figure 3: Interpreted redox zonation for each major sampling campaign. Information used to create

374 the 2006 interpretation is from the sampling campaign carried out in both 2006 and 2007. The

375 dotted line in the 2006 interpretation indicates the approximate location of the pyrite oxidation

376 front. Blank areas, without redox zonation, in each bottom corner of the figure represent areas with 
no data, where it is assumed that the original iron/manganese reducing condition of the aquifer remains.

From 2014 to 2017, little change was documented in the $\mathrm{O}_{2}$ and $\mathrm{NO}_{3}{ }^{-}$reducing zones. The maximum $\mathrm{O}_{2}$ concentration is $6.12 \mathrm{mg} \mathrm{L}^{-1}$ in 2017, compared to $6.40 \mathrm{mg} \mathrm{L}^{-1}$ in 2014 (Badin et al., 2016). In 2010, $\mathrm{O}_{2}$ measurements were below detection in the previously oxic part of the plume, presumably due to the DOC release (Badin et al., 2016). In 2017, $\mathrm{O}_{2}$ and $\mathrm{NO}_{3}{ }^{-}$concentrations are above $1 \mathrm{mg} \mathrm{L}^{-1}$ at depths above 10-15 mbgs and above 20 mbgs, respectively. While concentrations of $\mathrm{O}_{2}$ and $\mathrm{NO}_{3}{ }^{-}$are less than $0.1 \mathrm{mg} \mathrm{L}^{-1}$ below these depths, $\mathrm{Fe}(\mathrm{II})$ and $\mathrm{SO}_{4}{ }^{2-}$ appeared at concentrations of $0.36-0.45 \mathrm{mg} \mathrm{L}^{-1}$ and $43-61 \mathrm{mg} \mathrm{L}^{-1}$, respectively, indicating the location of the pyrite oxidation front at approximately 20 mbgs as described in the previous site investigations (Badin et al., 2016; Hunkeler et al., 2011).

Mixed redox conditions are still present near the source zone at the local scale, as was also documented in 2014, but not in 2006. As in 2014, $\mathrm{O}_{2}$ and $\mathrm{Fe}(\mathrm{II})$ are sometimes measured simultaneously in some screens within 20 mbgs and 100 m from the source (especially F2, F3 and F4). There are also some screens in this area where $\mathrm{NO}_{3}{ }^{-}$and $\mathrm{Fe}(\mathrm{II})$ are not detected, but methane is detected in low concentrations $\left(<0.01 \mathrm{mg} \mathrm{L}^{-1}\right)$. The DOC released by the thermal remediation (Friis et al., 2005) is still measured at its highest concentration, $6.9 \mathrm{mg} \mathrm{L}^{-1}$, in the mixed area, and is similar to the $6.1 \mathrm{mg} \mathrm{L}^{-1}$ measured in 2014. Mn(II) was not measured in 2014, but in 2017 was measured at low levels of $0.28-0.51 \mathrm{mg} \mathrm{L}^{-1}$ throughout the aquifer and appeared in its highest concentration, $3.9 \mathrm{mg} \mathrm{L}^{-1}$, in the mixed zone. In Badin et al., 2016, it was posited that this mixed zone was the result of local subsurface heterogeneity impacted at different rates by the DOC released by the thermal remediation. Anoxic pockets in mixed redox zones can provide ideal conditions for reductive dechlorination (Wiegert et al., 2012) and it is possible that this process 
occurs in this zone. Though the mixed zone has decreased in size, this effect of the thermal remediation is still present in 2017.

Just as the most marked change from 2006 to 2014 was the appearance of an $\mathrm{SO}_{4}{ }^{2-}$ reducing zone, the most marked change from 2014 to 2017 is that the $\mathrm{SO}_{4}{ }^{2-}$ reducing zone has become smaller. In 2014, Fe(II) was not detected from 1050 to 1400 m from the source zone. In 2017, Fe(II) is present throughout the aquifer at depths greater than 20 mbgs. Fe(II) concentrations at $1050 \mathrm{~m}$ downgradient in 2017 are $0.25-0.37 \mathrm{mg} \mathrm{L}^{-1}$, which is less than its presence in the remainder of the aquifer, at $0.47-1.2 \mathrm{mg} \mathrm{L}^{-1}$. $\mathrm{SO}_{4}{ }^{2-}$ concentrations in the aquifer at depths greater than 20 mbgs range from $36-50 \mathrm{mg} \mathrm{L}^{-1}$ as in the two previous sampling campaigns, where the lowest concentrations are concurrent with the lowest $\mathrm{Fe}(\mathrm{II})$ concentrations, in well B34. This indicates that $\mathrm{SO}_{4}{ }^{2-}$ reduction still occurs in this zone, but to a lesser extent than before - there is no longer enough biogenic sulfide, the product of $\mathrm{SO}_{4}{ }^{2-}$ reduction, to form iron-sulfide precipitates with all $\mathrm{Fe}(\mathrm{II})$ produced by pyrite oxidation. However, there is still a decrease in the $\mathrm{SO}_{4}{ }^{2-}$ concentration, which indicates that iron-sulfide precipitates, also referred to as reactive mineral intermediates, are still present at this location (Culpepper et al., 2018; Jeong et al., 2011).

The decrease in size of the $\mathrm{SO}_{4}{ }^{2-}$ reducing zone and the increased concentration of $\mathrm{O}_{2}$ since 2010 indicate that the redox conditions of the aquifer are returning to their state prior to the thermal remediation and influx of DOC in 2006. However, the conditions in the aquifer are still favorable for microbial respiration of cDCE and VC (Scheutz et al., 2010) in the mixed zone near the source and in the $\mathrm{SO}_{4}{ }^{2-}$ reducing section of the plume, between 1000 and $1200 \mathrm{~m}$ from the source.

\subsection{Evolution of chlorinated ethene concentrations}

The concentrations of PCE and its daughter compounds, TCE, CDCE, and VC, were measured in the plume as in previous sampling campaigns (Badin et al., 2016; Hunkeler et al., 2011) and data 
423 for 2017 are presented in Figure 4a. Ethene, ethane, and acetylene were also measured, but as in 424 previous campaigns, were not detected. The plume in general still follows the previously measured 425 centerline. 

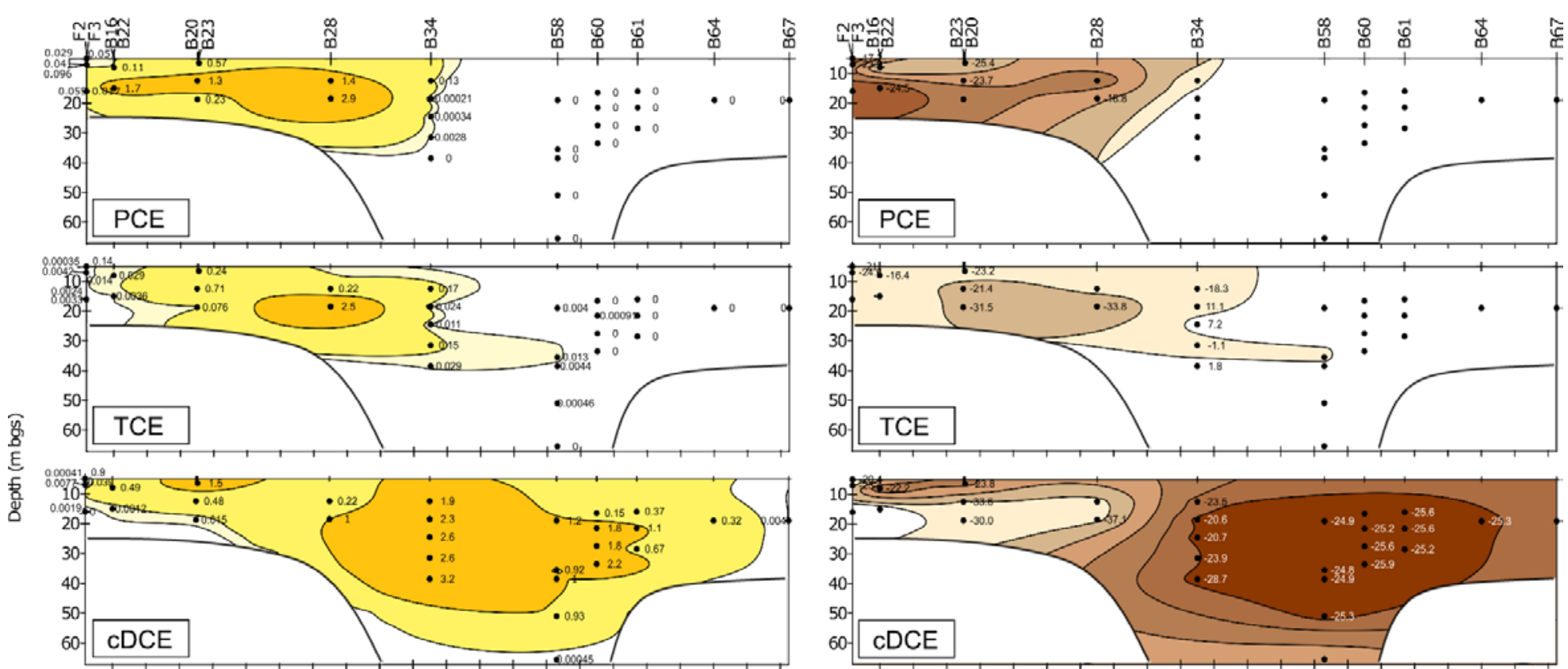

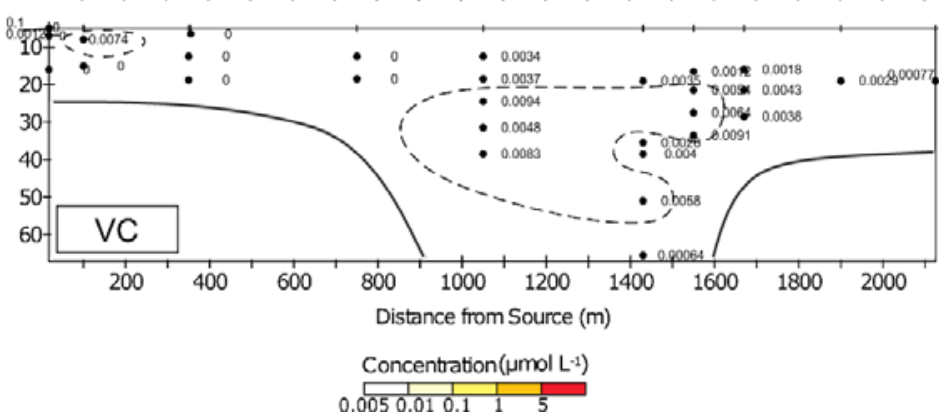

(a)
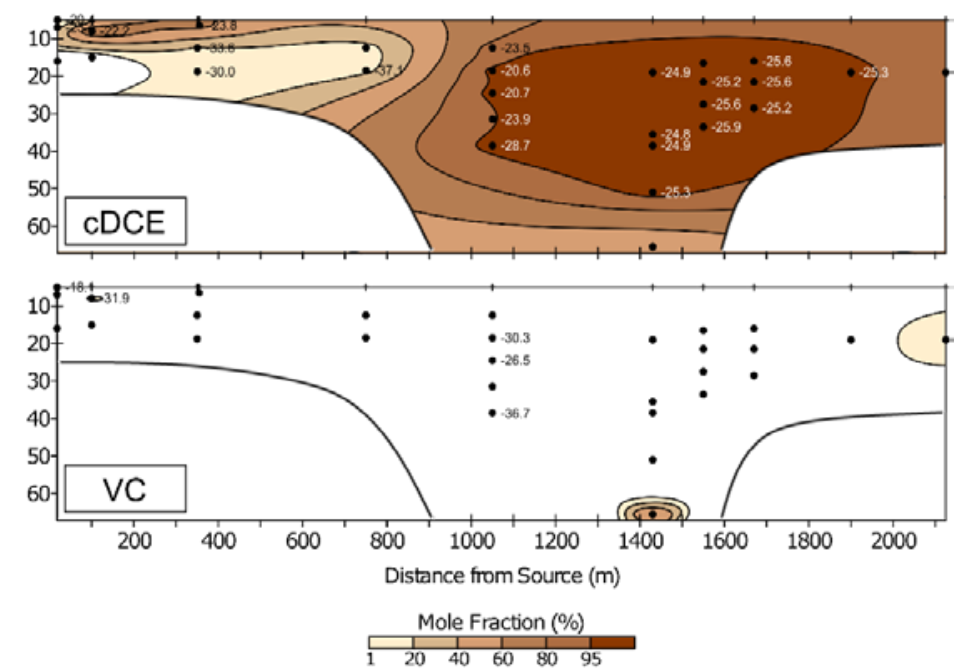

(b)

Figure 4: Chlorinated ethene concentrations (a) and mole fraction contours (b) in the subsurface from the 2017 sampling campaign. Data point labels indicate concentration measurements in (a) and $\delta^{13} \mathrm{C}$ measurements in (b), also from the 2017 sampling campaign. Blank areas, without contour information, in each bottom corner of the figure are areas with no data. 
PCE and TCE are still detected in the first $1050 \mathrm{~m}$ and $1400 \mathrm{~m}$ from the source, respectively, as in 2014, but the concentrations are generally lower than in 2014 and remain substantially lower than before the thermal remediation was conducted. The PCE and TCE centers of mass appear to have moved downgradient since 2014, although the maximum concentrations are found in the same boreholes. PCE still dominates the first $750 \mathrm{~m}$ of the plume by mole fraction (Figure 4b), especially 431 at depths greater than 10 mbgs, but unlike in 2014, PCE mole fractions over 85\% only occur near 432 the source zone. TCE concentrations within $350 \mathrm{~m}$ from the source have also decreased from 2014 to 2017, although the highest concentrations in B28, B34, and B58 have remained relatively constant.

cDCE remains the dominating chlorinated ethene in the plume, and the highest cDCE concentrations are still found in B34, $1050 \mathrm{~m}$ from the source, where the plume enters the more reducing zones of the aquifer. In the first $750 \mathrm{~m}$ of the plume, the mole fraction of cDCE has decreased since 2014, though it is still the dominating chlorinated ethene in the mixed zone at less than 10 mbgs within $350 \mathrm{~m}$ from the source. Concentrations measured near and at the plume front remain similar to those measured in 2014 and remain higher than what was measured before the remediation event in 2006.

VC is mostly detected from $1050 \mathrm{~m}$ from the source until the front of the plume, and VC concentrations are generally lower than in 2014 and 2006. The highest VC concentration was found in well B34, as was also the case in 2006 and 2014. The VC mole fraction at the plume front has 445 decreased from $40 \%$ in 2014 to $16 \%$ in 2017. While the maximum concentrations of cDCE and VC 446 in well B34 have moved further downgradient than in 2014, indicating that the plume is moving in 447 the longitudinal direction, there is no indication that the contaminants have moved the 150 to $500 \mathrm{~m}$ 448 estimated from the local pore water velocity calculations, which suggests that degradation is 449 occurring. 
451 The carbon and chlorine isotope values were measured as in the two previous sampling campaigns 452 (Badin et al., 2016; Hunkeler et al., 2011); the 2017 data is presented in Table S3, and the 453 distribution of carbon isotope values are shown on Figure $4 \mathrm{~b}$. The $\delta^{13} \mathrm{C}$ values have not changed 454 remarkably since 2014. The $\delta^{13} \mathrm{C}$ values for PCE are more enriched than the initial value, 455 previously estimated to be -25\%o (Hunkeler et al., 2011), in all but one sampling point. This 456 documents PCE degradation within the first $750 \mathrm{~m}$ from the source. The $\delta^{13} \mathrm{C}$ signatures for TCE in 457 this part of the plume indicate that TCE is produced and then even further degraded in some parts 458 above the pyrite oxidation front at approximately 20 mbgs. The most noteworthy degradation of 459 TCE occurs as the plume crosses the pyrite oxidation front at B34, $1050 \mathrm{~m}$ downgradient from the 460 source, with $\delta^{13} \mathrm{C}$ values of $+11 \%$ and $+7.2 \%$.

461 In the mixed redox zone, the first $350 \mathrm{~m}$ of the plume, the $\delta^{13} \mathrm{C}$ values for cDCE indicate production 462 followed by degradation, reaching a $\delta^{13} \mathrm{C}$ value of up to $-20.4 \%$. Within $350-750 \mathrm{~m}$ downgradient 463 from the source, cDCE production is primarily observed, with the lowest $\delta^{13} \mathrm{C}$ values of $-33.6 \%$ 464 and -37.1\%o. As the plume enters the sulfate reducing zone at B34, $1050 \mathrm{~m}$ downgradient from the 465 source, cDCE degradation occurs, with $\delta^{13} \mathrm{C}$ values from $-20.6 \%$ o to $-23.9 \%$, with the exception of 466 the deepest screen at $\sim 40$ mbgs where there is no documentation for degradation. From $1430 \mathrm{~m}$ to 467 the plume front, there is also no documentation for cDCE degradation, as the $\delta^{13} \mathrm{C}$ values are close 468 to the initial signature, with the exception of B76 at a distance of $1900 \mathrm{~m}$, where the $\delta^{13} \mathrm{C}$ is enriched 469 to -22.4\%o. However, a small amount of cDCE degradation could still occur but not be documented 470 if production is the dominant process.

471 Immediately downgradient from the source zone, a $\delta^{13} \mathrm{C}$ value for $\mathrm{VC}$ of $-18.1 \%$ suggests degradation, whereas values of $-26.5 \%$ o to $-36.7 \%$ indicate VC production at $100-1050 \mathrm{~m}$. From 
$1050 \mathrm{~m}$ to the plume front, the VC concentrations were too low for isotope analysis; isotope signatures can therefore not be used to assess if the produced VC is further degraded in this part of the plume. As with cDCE, the trend in B76 is an exception in the last part of the plume, where the $\delta^{13} \mathrm{C}$ for VC is enriched and thus indicates further degradation.

Since the contamination originates from one source, an isotopic mass balance can be applied to assess if all degradation products were accounted for (Aeppli et al. 2010; Blázquez-Palli et al. 2019) and was determined for all points with available isotope data (Table S3). Enriched $\delta^{13} \mathrm{C}_{\text {sum }}$ values are found within the first $100 \mathrm{~m}$, at $1050 \mathrm{~m}$ (B34), and at $1900 \mathrm{~m}$ (B76) from the source. These areas correspond to where cDCE degradation is documented by the $\delta^{13} \mathrm{C}$ values. VC is detected at these locations, and though isotope signatures are not available at all locations to document further dechlorination, it is possible that this enrichment could be due to further degradation of VC. This would indicate that degradation of cDCE is the rate limiting step in the dechlorination process. However, the enrichment could also be an effect of cDCE degradation by a different process without significant VC production, e.g. abiotic degradation by iron minerals below the pyrite oxidation front (Lee and Batchelor, 2002a). End-products of anaerobic reductive dechlorination (ethene and ethane) and of abiotic degradation by e.g. pyrite (acetylene, ethene, and ethane) were not detected and could not be used for clarification. The remaining points have a $\delta^{13} \mathrm{C}_{\text {sum }}$ value close to the initial value, indicating that all contaminants are accounted for and that a limited reduction of the total contaminant mass occurs at $350 \mathrm{~m}$ and again from $1450 \mathrm{~m}$ to the front of the plume.

The isotope time series data also provide information about areas of the plume between sampling points. As an example, the enrichment in $\delta^{13} \mathrm{C}$ signatures for cDCE observed at $1050 \mathrm{~m}$ in 2014 still occurs in 2017, but the enriched signatures are not observed in the downgradient monitoring wells at $1430 \mathrm{~m}$. Given the average pore water velocities (Section 4.1), the transport time between these 
496 locations is approximately 4-5 years. Because the less enriched values documented in the sulfate 497 reducing zone in 2014 are not measured at $1430 \mathrm{~m}$ from the source in 2017, the zone where cDCE 498 was degraded in 2014 must have been less than $200 \mathrm{~m}$ in length. The data also indicate that the

499 degradation zone was not present in 2010, as again, less enriched cDCE isotope signatures would 500 have been detected downgradient in the 2017 sampling campaign. This corresponds well with redox 501 parameters measured in 2010, as Fe(II) was present and the sulfate reducing zone was only 502 beginning to form at well B34, and supports the process understanding of the plume evolution.

\subsubsection{Dual C-Cl isotope plots}

504 Dual-isotope plots for all monitored years (2006 (Hunkeler et al., 2011), 2014 (Badin et al., 2016), 505 and 2017) are presented in Figure 5, to provide insight into degradation pathways and changes over 506 time. For the dual-isotope assessment, these slopes are compared to other reported slopes related to 507 different pathways for the individual compounds (Table 1). 


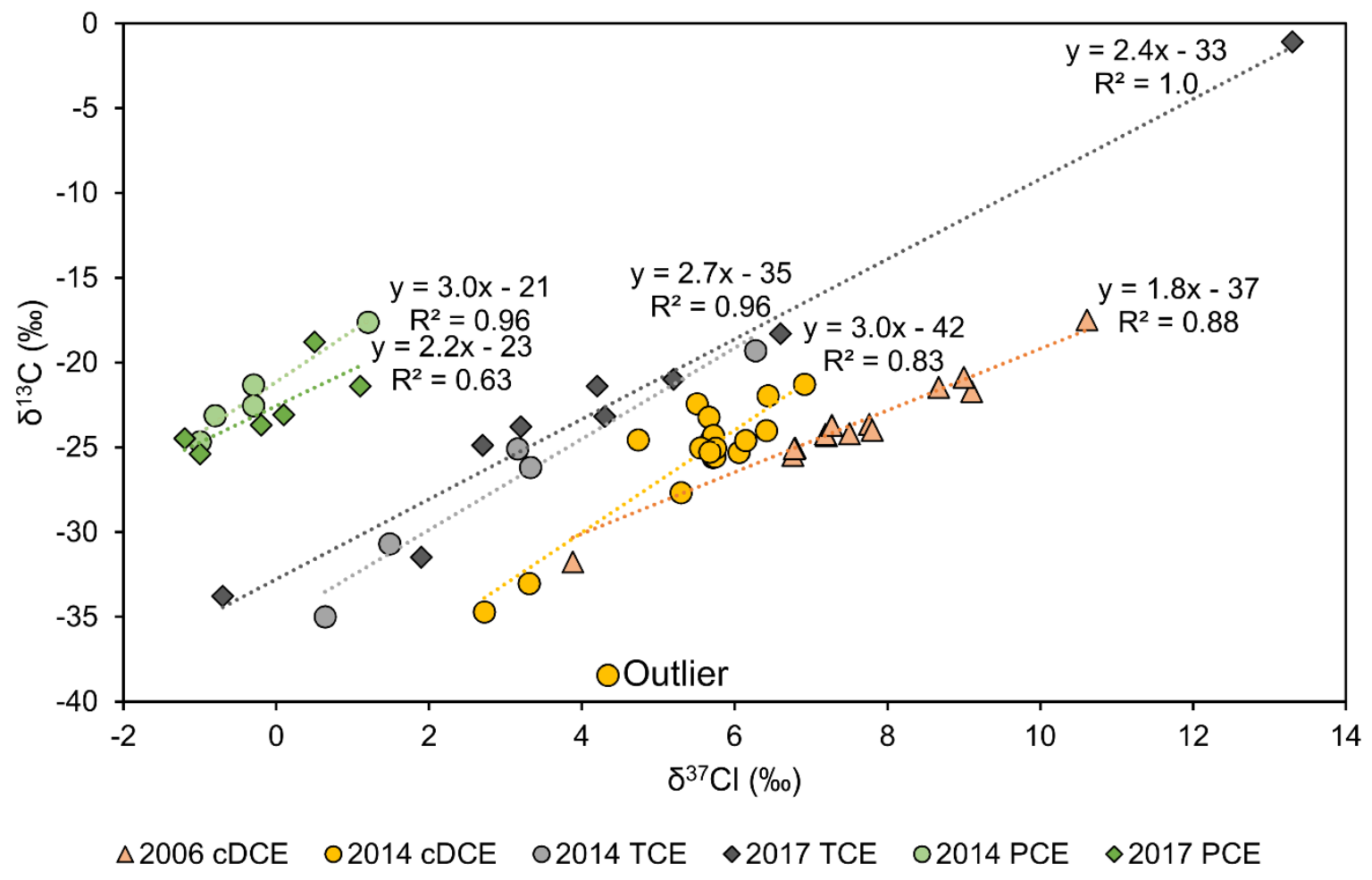

509 Figure 5: Dual C-Cl isotope slopes for PCE, TCE, and cDCE degradation. Results are included

510 from the current sampling campaign as well as the two previous sampling campaigns in 2006

511 (Hunkeler et al., 2011) and 2014 (Badin et al., 2016).

512 Table 1: Dual C-Cl isotope slopes compared with values from the literature for PCE, TCE, and

513 cDCE degradation at the field and laboratory scales. Some slopes have been converted to ensure the

514 same ratio and allow for comparison between all data, the original reported slopes are included in

515 parentheses.

\begin{tabular}{|c|c|c|c|c|}
\hline Degradation process & Compound & Scale & $\begin{array}{l}\text { Dual isotope } \\
\text { slope }\left(\varepsilon_{\mathrm{C}} / \varepsilon_{\mathrm{Cl}}\right)\end{array}$ & Reference \\
\hline \multirow{3}{*}{ Abiotic } & TCE & Laboratory & $5.2 \pm 0.3$ & (Audí-Miró et al., 2013) \\
\hline & \multirow[b]{2}{*}{ cDCE } & Laboratory & $3.1 \pm 0.2$ & (Audí-Miró et al., 2013) \\
\hline & & Laboratory & $5.0 \pm 0.6$ & (Audí-Miró et al., 2013) \\
\hline \multirow{7}{*}{$\begin{array}{c}\text { Biotic anaerobic reductive } \\
\text { dechlorination }\end{array}$} & \multirow{7}{*}{ PCE } & Field & 0.9 & (Wiegert et al., 2012) $\left(\varepsilon_{\mathrm{Cl}} / \varepsilon_{\mathrm{C}}=1.12\right)$ \\
\hline & & Field & 2.4 & (Wiegert et al., 2012) $\left(\varepsilon_{\mathrm{Cl}} / \varepsilon_{\mathrm{C}}=0.42\right)$ \\
\hline & & Field & $0.7 \pm 0.3$ & (Badin et al., 2014) \\
\hline & & Field & $3.5 \pm 1.6$ & (Badin et al., 2014) \\
\hline & & Field & 2.2 & This study (2017) \\
\hline & & Field & 3.0 & This study (2014) \\
\hline & & Laboratory & 2.9 & (Wiegert et al., 2013) $\left(\varepsilon_{\mathrm{Cl}} / \varepsilon_{\mathrm{C}}=0.35\right)$ \\
\hline
\end{tabular}




\begin{tabular}{|c|c|c|c|c|}
\hline Degradation process & Compound & Scale & $\begin{array}{l}\text { Dual isotope } \\
\text { slope }\left(\varepsilon_{\mathrm{C}} / \varepsilon_{\mathrm{Cl}}\right)\end{array}$ & Reference \\
\hline & & Laboratory & $2.7 \pm 0.3$ & (Badin et al., 2014) \\
\hline & & Laboratory & $0.7 \pm 0.2$ & (Badin et al., 2014) \\
\hline & & Laboratory & $3.8 \pm 0.2$ & (Cretnik et al., 2014) \\
\hline & \multirow{18}{*}{ TCE } & Field & 2.4 & \multirow{18}{*}{$\begin{array}{l}\text { This study (2017) } \\
\text { This study (2014) } \\
\left.\text { (Wiegert et al., 2013) ( } \varepsilon_{\mathrm{Cl}} / \varepsilon_{\mathrm{C}}=0.37\right) \\
\text { (Cretnik et al., 2013) } \\
\text { (Cretnik et al., 2013)(Cretnik et al., } \\
\text { 2013) } \\
\text { (Kuder et al., 2013) ( } \varepsilon_{\mathrm{Cl}} / \varepsilon_{\mathrm{C}}=0.21 \text { ) } \\
\text { (Buchner et al., 2015) } \\
\text { (Buchner et al., 2015) (Buchner et al., } \\
\text { 2015) (Buchner et al., 2015) (Lihl et al., } \\
\text { 2019) } \\
\text { (Lihl et al., 2019) (Lihl et al., 2019) } \\
\text { (Lihl et al., 2019) (Lihl et al., 2019) } \\
\text { (Lihl et al., 2019) (Lihl et al., 2019) }\end{array}$} \\
\hline & & Field & 2.7 & \\
\hline & & Laboratory & 2.7 & \\
\hline & & Laboratory & $3.4 \pm 0.2^{\mathrm{a}}$ & \\
\hline & & Laboratory & $3.4 \pm 0.2^{\mathrm{a}}$ & \\
\hline & & Laboratory & $3.8 \pm 0.2$ & \\
\hline & & Laboratory & 4.8 & \\
\hline & & Laboratory & $3.2 \pm 0.2$ & \\
\hline & & Laboratory & $3.4 \pm 0.2$ & \\
\hline & & Laboratory & $2.8 \pm 0.3$ & \\
\hline & & Laboratory & $3.5 \pm 0.2$ & \\
\hline & & Laboratory & $3.1 \pm 0.1$ & \\
\hline & & Laboratory & $2.7 \pm 0.2$ & \\
\hline & & Laboratory & $2.3 \pm 0.1$ & \\
\hline & & Laboratory & $11.8 \pm 2.4$ & \\
\hline & & Laboratory & $18.2 \pm 4.3$ & \\
\hline & & Laboratory & $9.0 \pm 1.1$ & \\
\hline & & Laboratory & $4.5 \pm 0.8$ & \\
\hline & \multirow{6}{*}{ cDCE } & & 13.7 & \\
\hline & & Laboratory & 11.4 & (Abe et al., 2009) $\left(\varepsilon_{\mathrm{Cl}} / \varepsilon_{\mathrm{C}}=0.073\right)$ \\
\hline & & Laboratory & $4.5 \pm 3.4$ & (Abe et al., 2009) $\left(\varepsilon_{\mathrm{Cl}} / \varepsilon_{\mathrm{C}}=0.088\right)$ \\
\hline & & Laboratory & $10.0 \pm 0.4$ & (Doğan-Subaşı et al., 2017) \\
\hline & & Laboratory & $17.8 \pm 1.0$ & (Lihl et al., 2019) (Lihl et al., 2019) \\
\hline & & Laboratory & & \\
\hline \multirow{3}{*}{$\begin{array}{l}\text { Combined biotic and } \\
\text { abiotic }\end{array}$} & \multirow{3}{*}{ cDCE } & Field & $1.5 \pm 0.15^{\mathrm{b}}$ & (Audí-Miró et al., 2015) \\
\hline & & Field & 3.0 & This study (2014) \\
\hline & & Field & 1.8 & This study (2006) \\
\hline \multirow{5}{*}{ Oxidation } & \multirow{3}{*}{ TCE } & Laboratory & $1.7 \pm 0.4^{\mathrm{C}}$ & (Gafni et al., 2018) \\
\hline & & Laboratory & $-38 \pm 27^{c}$ & (Gafni et al., 2018) \\
\hline & & Laboratory & $\infty^{\mathrm{d}}$ & (Doğan-Subaşı et al., 2017) \\
\hline & \multirow{2}{*}{ cDCE } & Laboratory & $32.3^{\mathrm{c}}$ & (Abe et al., 2009) $\left(\varepsilon_{\mathrm{Cl}} / \varepsilon_{\mathrm{C}}=0.031\right)$ \\
\hline & & Laboratory & $-125 \pm 47^{d}$ & (Doğan-Subaşı et al., 2017) \\
\hline
\end{tabular}

516 aThis value was found twice in the study but for two different microbial strains: G. lovleyi SZ and D. hafniense Y51.

517 bCombined biotic anaerobic reductive dechlorination and abiotic degradation by iron minerals, but with the former

518 dominating. ${ }^{\mathrm{c}}$ Microbial aerobic oxidation. ${ }^{\mathrm{d}}$ Oxidation by permanganate.

519 The dual C-Cl slope for PCE of 2.2 found in 2017 corresponds well with the slope of 3.0 obtained

520 in 2014. These values are within the range of the reported slopes for microbial reductive

521 dechlorination (0.7 to 3.8), which is one of the most well documented degradation pathways for

522 chlorinated ethenes by the dual $\mathrm{C}$-Cl isotope technique (Table 1). This supports that PCE is

523 degraded by biotic reductive dechlorination within the first $750 \mathrm{~m}$ of the plume, however slopes that 
correspond to other pathways have yet to be defined for PCE. Nonetheless, the likelihood that this pathway occurs is also supported by the high concentration of the intermediate product TCE.

At the current knowledge level, the reported slopes (Table 1) are not a strong indicator to determine the degradation pathway for TCE at the field site. First, because recent investigation of slopes related to TCE oxidation (-38 to 1.7) covers a great span, as the investigated strains, Pseudomonas putida F1 and Methylosinus trichosporium OB3b, produce degradation related slopes that are both steeper and more gradual than the slopes of the other pathways. Gafni et al., 2018 does state that

531 further research is required to resolve uncertainties about whether the OB3b strain that led to the 1.7 532 slope is representative of this pathway. If this result is excluded from the range corresponding to 533 TCE oxidation (-38 to $\infty$ ), the slopes related to this pathway can be separated from the others. 534 Secondly, Lihl et al., 2019 recently found that cultures precultivated on DCE and VC provided steeper slopes (9.0-18.2) for TCE dechlorination than the commonly reported range (2.3-4.8). Thus, biotic and abiotic slopes for TCE degradation overlap, as the only reported slope for abiotic TCE reduction (5.2) is within the range of biotic reductive dechlorination (2.3-18.2). The dual C-Cl slopes for TCE of 2.4 and 2.7 found at this study site, in 2017 and 2014, respectively, are lower than the reported slope for abiotic degradation, which could indicate that TCE degradation in the 540 first $1050 \mathrm{~m}$ of the plume is primarily due to biotic reductive dechlorination. This is supported by 541 the significant production of cDCE throughout the plume. However, additional investigation is 542 required to strengthen the applicability of the dual C-Cl isotope approach to assess TCE degradation 543 pathways.

544 For cDCE, it was not possible to obtain $\delta^{37} \mathrm{Cl}$ results in 2017 , and it is therefore not possible to 545 evaluate if the observed change in slope from 1.8 to 3.0 in 2006 to 2014 remains. In 2014, it was 546 assessed that cDCE degradation was predominantly abiotic (3.1 to 5.0), as the slopes did not match 547 reported values for microbial reductive dechlorination (11.4-13.7) at the time (Table 1). The same 
conclusion can be drawn including new slopes reported in the literature: abiotic (3.1 to 5.0),

549 chemical oxidation (-125), microbial oxidation (32.3), and microbial reductive dechlorination (4.5

550 to 17.8) (Table 1). It is notable that the slope range for microbial reductive dechlorination is now

551 closer to the slopes found in the Rødekro site investigations. The slopes found at Rødekro are also

552 comparable to a slope recently reported for combined biotic reductive dechlorination and abiotic

553 dechlorination (1.5) (Table 1). The possibility that both degradation pathways occur in the plume

554 for cDCE should therefore not be dismissed. This is elaborated upon in combination with other

555 lines of evidence in Section 5.

556 Dual C-Cl isotope slopes can provide site specific enrichment factors $\left(\varepsilon_{\mathrm{C}}\right)$. The parallel trend 557 between the PCE and TCE slopes confirms that PCE is the precursor to TCE. The offset of the 558 intercepts on the $\delta^{13} \mathrm{C}$ axis can thus be used to determine the $\varepsilon_{\mathrm{C}}$ for this degradation step (Hunkeler 559 et al., 2009). This results in an enrichment factor of -8.4\%o in 2017; for comparison it was estimated 560 to be $-10.3 \%$ based on the 2014 dataset. It is viable to apply dual isotope analysis to estimate the 561 enrichment factor at the field scale, as this estimation method is not dependent on concentration and 562 therefore not impacted by dispersion and transport processes. Further, the data used for the $\varepsilon_{\mathrm{C}}$ 563 estimation is not the same as that used for estimation of the extent of degradation and degradation 564 rates. These site-specific enrichment factors are within the range of earlier reported values of $565-3.6 \%$ (Badin et al., 2014), -5.6\%o (Wiegert et al., 2013) and -19.0\%o (Cretnik et al., 2014).

\subsubsection{Quantification of degradation by isotope fractionation}

567 The extent of degradation was calculated by Equation 3 for PCE in the first $750 \mathrm{~m}$ of the plume and 568 for cDCE from $1050 \mathrm{~m}$ to the plume front (Table S3), as this estimation can only be done for 569 compounds that solely are degraded (Badin et al., 2016). This approach has been applied 570 successfully at several field sites (e.g. Aeppli et al., 2010; Lollar et al., 2001) and uncertainties 
related to this estimation method have been assessed to be relatively low (Abe and Hunkeler, 2006; Thullner et al., 2012).

The extent of PCE and cDCE degradation are comparable between 2014 and 2017, as would be expected since the $\delta^{13} \mathrm{C}$ values are similar in both sampling campaigns. The main development is that the extent of PCE degraded at B28-1 (750 m downgradient) has increased from 30\% to 52\%. The largest proportion of degraded PCE is estimated to be 61\% in F3-3 (18 m downgradient), while the average extent of PCE degradation is $29 \%$ in the first $750 \mathrm{~m}$ of the plume. This demonstrates that degradation varies spatially, and that a significant proportion of PCE must be degraded between $750 \mathrm{~m}$ and $1050 \mathrm{~m}$ downgradient from the source. The estimation of degraded cDCE is more uncertain, since a site-specific enrichment factor related to cDCE degradation could not be obtained. The largest proportion of degraded cDCE is estimated to lie between $13 \%$ and $47 \%$ and is found in B34-4, 1050 m downgradient from the source zone. In B58, 1430 m downgradient, at most $2 \%$ of cDCE is estimated to be degraded, which illustrates that cDCE is chiefly degraded in the sulfate reducing zone.

The isotope data can also be applied to derive degradation rates, and though there is some uncertainty related to the input parameters, it is still suggested to be a more accurate approach than determining rates from concentrations (Abe and Hunkeler, 2006; Morrill et al., 2005). Local degradation rates were calculated for PCE (Table 2) by dividing the plume into two flow zones from 18-350 m and from 350-750 m downgradient from the source (see Supplementary Information for more information on flow assumptions). The apparent degradation rate for the first $350 \mathrm{~m}$ (0.12 $\left.\mathrm{yr}^{-1}\right)$ is three times lower than the rate for $350 \mathrm{~m}$ to $750 \mathrm{~m}\left(0.35 \mathrm{yr}^{-1}\right)$. The estimated degradation rate $\left(0.25 \mathrm{yr}^{-1}\right)$ for the entire length $(0-750 \mathrm{~m})$ demonstrates that averaging over a longer distance masks the local variation, and it is thus important to determine local pore water velocities if the isotope signatures indicate local degradation zones. The degradation rates between the same 
595 boreholes and screens were also estimated using data from previous sampling campaigns, under the 596 assumption that flow conditions were the same. The estimated degradation rate for the first $350 \mathrm{~m}$ 597 of the plume compares well between $2006\left(0.17 \mathrm{yr}^{-1}\right), 2014\left(0.14 \mathrm{yr}^{-1}\right)$ and $2017\left(0.12 \mathrm{yr}^{-1}\right)$, though 598 the degradation rate appears to become slower over time. There is a more remarkable change from $599350 \mathrm{~m}$ to $750 \mathrm{~m}$, as the estimated rate is approximately 3 times larger in $2017\left(0.35 \mathrm{yr}^{-1}\right)$ compared 600 to $2014\left(0.11 \mathrm{yr}^{-1}\right)$, though similar to the rate from $2006\left(0.41 \mathrm{yr}^{-1}\right)$. The difference is caused by a 601 weaker enrichment of PCE in B28-1 (750 m downgradient) in 2014, contrary to what would have 602 been expected from the development in redox conditions. The data reveal that degradation 603 quantification estimations are sensitive to redox conditions not only in the longitudinal direction but 604 also in the vertical direction; as an example another screen measured in 2014, B23-2, would have 605 provided a degradation rate of $0.53 \mathrm{yr}^{-1}$ between the source and $350 \mathrm{~m}$ downgradient (compared to 606 the $0.14 \mathrm{yr}^{-1}$ above). It is therefore important to combine this assessment with other lines of 607 evidence to understand at which spatial orientation it is most reasonable to assume similar 608 conditions and thus which estimated degradation rates are most representative for a given stretch of 609 the plume. Regardless, neither estimated rate is large enough to completely degrade PCE within the 610 first $750 \mathrm{~m}$. Although there is some variation in the estimated degradation rates, they are in general 611 at the low end of the literature reported range of 0.3-7.3 $\mathrm{yr}^{-1}$ (Ottosen et al., 2019). Thus, PCE 612 degradation likely continues between $750 \mathrm{~m}$ and $1050 \mathrm{~m}$ downgradient from the source, as the 613 plume crosses the pyrite oxidation front and enters the sulfate-reducing zone. Indeed, the PCE 614 concentration drops so low between these locations (Figure 4) that isotope analysis was not possible 615 at $1050 \mathrm{~m}$ downgradient from the source. 
Table 2: Estimated degradation rates for PCE and CDCE as a function of distance and time, where $L$

$617=$ distance for calculation, $t=$ time frame for calculation, $V_{p}=$ pore water velocity at calculation

618 location (more information in SI), $k=$ degradation rate, and $t_{1 / 2}=$ contaminant half-life

\begin{tabular}{|c|c|c|c|c|c|c|c|c|c|}
\hline & Part of plume & $\begin{array}{c}\varepsilon_{C} \\
(\% o)\end{array}$ & $\begin{array}{c}\delta^{13} C_{0} \\
(\%)\end{array}$ & $\begin{array}{l}\delta^{13} C \\
(\% o)\end{array}$ & $\begin{array}{c}\mathrm{L} \\
(\mathrm{m})\end{array}$ & $\begin{array}{c}t \\
(y r)\end{array}$ & $\begin{array}{c}V_{p} \\
\left(\mathrm{~m} \mathrm{yr}^{-1}\right)\end{array}$ & $\begin{array}{c}\mathbf{k} \\
\left(\mathrm{yr}^{-1}\right)\end{array}$ & $\begin{array}{c}t_{1 / 2} \\
(y r)\end{array}$ \\
\hline \multirow{3}{*}{$\begin{array}{l}\text { PCE } \\
2017\end{array}$} & $0-350 \mathrm{~m}$ & \multirow{3}{*}{-8.4} & -25 & -23.7 & 350 & - & 306 & 0.12 & 5.8 \\
\hline & $350-750 m$ & & -23.7 & -18.8 & 400 & - & 281 & 0.35 & 2.0 \\
\hline & $0-750 \mathrm{~m}$ & & -25 & -18.8 & 750 & - & 294 & 0.25 & 2.8 \\
\hline \multirow{3}{*}{$\begin{array}{l}\text { PCE } \\
2014\end{array}$} & $0-350 \mathrm{~m}$ & \multirow{3}{*}{-10.3} & -25 & -23.1 & 350 & - & 306 & 0.14 & 5.0 \\
\hline & $350-750 m$ & & -23.1 & -21.3 & 400 & - & 281 & 0.11 & 6.3 \\
\hline & $0-750 \mathrm{~m}$ & & -25 & -21.3 & 750 & - & 294 & 0.12 & 5.8 \\
\hline \multirow{3}{*}{$\begin{array}{l}\text { PCE } \\
2006\end{array}$} & $0-350 \mathrm{~m}$ & \multirow{3}{*}{-10.3} & -25 & -22.6 & 350 & - & 306 & 0.17 & 4.1 \\
\hline & $350-750 m$ & & -22.6 & -15.5 & 400 & - & 281 & 0.41 & 1.7 \\
\hline & $0-750 \mathrm{~m}$ & & -25 & -15.5 & 750 & - & 294 & 0.31 & 2.2 \\
\hline cDCE & 1050m (B34-3) & $-6.9 \&$ & -21.3 & -20.7 & - & 3 & - & $0.03-0.01$ & $23-69$ \\
\hline 2014-2017 & 1050m (B34-4) & -31.1 & -22 & -20.6 & - & 3 & - & $0.07-0.02$ & $10-35$ \\
\hline $\begin{array}{c}\text { PCE } \\
2014-2017\end{array}$ & 750m (B28-1) & $\begin{array}{c}-8.4 \& \\
-10.3\end{array}$ & -21.2 & -18.8 & - & 3 & - & $0.10-0.08$ & 6.9-8.7 \\
\hline
\end{tabular}

The degradation observed for cDCE was so localized that degradation rates over distance could not be estimated from the 2017 data. However, because degradation occurred in the same area in 2014 and 2017, a degradation rate can be calculated through time rather than space. The rate was estimated for two depths at $1050 \mathrm{~m}$ downgradient from the source where there was enrichment over time, which revealed maximum degradation rates of $0.03 \mathrm{yr}^{-1}$ and $0.07 \mathrm{yr}^{-1}$. These degradation rates 625 are low compared to the literature reported range of 0.3-3.3 $\mathrm{yr}^{-1}$ (Ottosen et al., 2019). The results highlight the importance of determining site-specific enrichment factors, as the literature reported $\varepsilon_{\mathrm{c}}$ range resulted in at least a three-fold difference in the estimated degradation rates.

628 A time-based degradation rate was also estimated for PCE in B28-1, where the change of 629 degradation extent was greatest between 2014 and 2017. Interestingly, the degradation rate found at 630 this one location, at $750 \mathrm{~m},\left(0.08 \mathrm{yr}^{-1} 1\right.$ or $0.10 \mathrm{yr}^{-1}$, depending on the applied enrichment factor $)$ is 631 equivalent to the one found between immediately downgradient from the source and $750 \mathrm{~m}\left(0.12 \mathrm{yr}^{-}\right.$ $632{ }^{1}$ ). The travel time from the source to $750 \mathrm{~m}$ downgradient is approximately three years, the same 
period as is evaluated in the time-based degradation rate; the estimated rate in one location over

634 time corresponds to what occurred over the upgradient distance in the same time frame.

In order to further understand the extent to which chlorinated ethene biodegradation processes occur conducted for the genera Dehalococcoides and Dehalogenimonas. Activity transcription analysis based on RNA was also conducted for Dehalococcoides, bvcA and vcrA. It is not uncommon for RNA extraction to be unsuccessful for subsurface samples (Richards et al., 2019), and RNA was only quantifiable in three samples. However, in these three screens where RNA was quantifiable, the qPCR signal was indistinguishable from the acceptable negative control, which indicates either no activity or that insufficient biomass was collected in the sample.

Table 3: Quantitative organohalide respiration relevant genera and functional gene data, as analyzed by Microbial Insights; bd = below detection, where the detection limit is $1.00 \mathrm{e} 2$ cell $\mathrm{L}^{-1}$ or copies $\mathrm{L}^{-}$

${ }^{1}$ for all analyses except cerA, where detection limits are indicated in the table.

\begin{tabular}{|c|c|c|c|c|c|c|c|}
\hline Well-Screen & F3-3 & F4-3 & B23-1 & B34-3 & B58-6 & B61-1 & B75-1 \\
\hline Distance from Source (m) & 18 & 18 & 350 & 1050 & 1430 & 1670 & 1670 \\
\hline Depth (m bgs) & 5 & 5 & 19 & 24.5 & 19 & 28.5 & 26.5 \\
\hline Dehalococcoides spp. (cells $\mathrm{L}^{-1}$ ) & $1.40 \times 10^{5}$ & $1.10 \times 10^{5}$ & $5.00 \times 10^{2}$ & $4.10 \times 10^{3}$ & bd & $5.00 \times 10^{2}$ & $4.00 \times 10^{2}$ \\
\hline vcrA (copies $\left.\mathrm{L}^{-1}\right)$ & $4.80 \times 10^{3}$ & $1.70 \times 10^{3}$ & $1.00 \times 10^{2 \mathrm{a}}$ & bd & bd & bd & bd \\
\hline bvcA (copies $\left.\mathrm{L}^{-1}\right)$ & $3.40 \times 10^{4}$ & $2.10 \times 10^{4}$ & bd & $2.30 \times 10^{3}$ & bd & bd & bd \\
\hline Dehalogenimonas spp. (cells L $\mathrm{L}^{-1}$ ) & $2.80 \times 10^{6}$ & $3.70 \times 10^{6}$ & $9.00 \times 10^{4}$ & $4.90 \times 10^{4}$ & $2.90 \times 10^{3}$ & $6.10 \times 10^{3}$ & $3.00 \times 10^{2 b}$ \\
\hline $\operatorname{cerA}\left(\operatorname{copies} \mathrm{L}^{-1}\right)$ & $1.80 \times 10^{3 \mathrm{c}}$ & $2.00 \times 10^{3 \mathrm{~d}}$ & $b d^{e}$ & $b d^{e}$ & $b^{e}{ }^{e}$ & $b d^{f}$ & $\mathrm{bd}^{\mathrm{g}}$ \\
\hline Dehalobacter spp. (cells L ${ }^{-1}$ ) & $1.96 \times 10^{6}$ & $7.55 \times 10^{5}$ & $3.32 \times 10^{4}$ & $4.36 \times 10^{5}$ & $4.52 \times 10^{5}$ & $6.93 \times 10^{5}$ & $1.22 \times 10^{6}$ \\
\hline Desulfitobacterium spp. (cells $\mathrm{L}^{-1}$ ) & $1.55 \times 10^{6}$ & $1.74 \times 10^{6}$ & $4.10 \times 10^{4}$ & $2.21 \times 10^{4}$ & $4.66 \times 10^{4}$ & $1.68 \times 10^{4}$ & $8.40 \times 10^{4}$ \\
\hline Desulfuromonas spp. (cells $\mathrm{L}^{-1}$ ) & $1.23 \times 10^{7}$ & $3.99 \times 10^{7}$ & $1.44 \times 10^{6}$ & $9.81 \times 10^{4}$ & $3.80 \times 10^{6}$ & $1.89 \times 10^{5}$ & $5.88 \times 10^{6}$ \\
\hline
\end{tabular}


limit of $6.70 \times 10^{1}$ copies $\mathrm{L}^{-1}$, e detection limit of $5.00 \times 10^{1}$ copies $\mathrm{L}^{-1},{ }^{\mathrm{f}}$ detection limit of $5.10 \times 10^{1}$ copies $\mathrm{L}^{-1}, \mathrm{~g}$

651 detection limit of $6.90 \times 10_{1}$ copies $\mathrm{L}^{-1}$.

652 Both Dehalococcoides and Dehalogenimonas were detected throughout the plume, with the highest 653 concentrations of $1.4 \times 10^{5}$ cells $\mathrm{L}^{-1}$ and $3.7 \times 10^{6}$ cells $\mathrm{L}^{-1}$, respectively, found just down gradient of 654 the source zone (Table 3). These abundances are comparable to those found in similar naturally degrading plumes (Damgaard et al., 2013). It is prudent to note, however, that microbial abundance measurements from groundwater samples have limitations. Groundwater samples allow collection of only those microorganisms that are not sorbed to the porous media (Griebler et al., 2009) and may not accurately represent what is present in the subsurface. Additionally, microbial community composition and the abundance of specific degraders in the subsurface varies greatly at the centimeter scale, as was determined with high resolution sampling in Damgaard et al., 2013 and Richards et al., 2019. Discrete sediment sampling in a deep, saturated sandy aquifer, as is found at Rødekro, is not feasible. The abundances presented in Table 3 represent a large sample collection area, and relatively few samples were collected along a plume length of $2 \mathrm{~km}$. While there are

664 limitations that may prevent, for example, rate quantification based on microbial populations, 665 microbial abundance measurements from groundwater samples do reflect OHRB distribution throughout the plume, and knowledge of which OHRB are present along the contaminant plume is requisite for process understanding.

In well B34-3, in the sulfate reducing zone where conditions are favorable for biotic degradation of cDCE and VC, both Dehalococcoides and Dehalogenimonas were present, however Dehalococcoides was not at all detected in B58-6, the first well after the sulfate reducing zone.

671 Dehalogenimonas was present in higher amounts than Dehalococcoides in all measured locations except in B75-1, 1680 m from the source zone, where both concentrations were lowest; both concentrations here were three and four orders of magnitude lower than the highest concentrations 
nearest the source zone. Auxiliary analyses conducted at Aarhus University show that both specific degrader genera were also detected at B16-1 and B17-1, approximately $100 \mathrm{~m}$ from the source zone (Table S4). Prior to recognition of the Dehalogenimonas capability to use cDCE and VC as electron acceptors (Yang et al., 2017), those wells with no measured Dehalococcoides population would not be identified as exhibiting the potential for complete dechlorination. In other studies, Dehalogenimonas may be present in locations where Dehalococcoides was not detected but lower chlorinated ethenes were detected (Badin et al., 2016; Nijenhuis et al., 2007). The presence of these known degraders, especially at higher concentrations immediately downgradient from the source zone, indicates the possibility that the microbial community is capable of complete biotic reduction of PCE to ethene.

The genera Dehalobacter, Desulfitobacterium, and Desulfuromonas, which contain species that are capable of partial PCE dechlorination, were detected at relatively high concentrations throughout the plume. Dehalobacter was detected in the pyrotag sequencing analysis in 2014, but the Microbial Insights QuantArray analysis is the first documentation of presence of Desulfitobacterium and Desulfuromonas in the Rødekro plume.

Dehalococcoides VC reductase genes vcrA and $b v c A$ were detected within $1050 \mathrm{~m}$ from the source zone (Table 3), where $\delta^{13} \mathrm{C}$ indicate cDCE degradation. Auxiliary analyses at Aarhus University 691 detected vcrA at wells within $100 \mathrm{~m}$ from the source (Table S4). The cerA gene from 692 Dehalogenimonas, which codes for the enzyme responsible for reductive dechlorination of vinyl 693 chloride to ethene (Yang et al., 2017), was only detected in F3-3 and F4-3, directly downgradient 694 from the source zone. Expression of the genes to respire VC is a positive indication of the occurrence of this process in this portion of the plume (Liang et al., 2017); non-detection of the 696 genes does not indicate the reverse, as other currently unidentified genes or bacteria may be capable 697 of carrying out this respiration process. 


\begin{tabular}{rccccccccccc}
\hline Well-Screen & F2-2 & F4-3 & B16-1 & B17-1 & B23-1 & B23-3 & B34-4 & B58-2 & B58-6 & B61-1 & B64-1 \\
\hline Distance (m) & 18 & 18 & 100 & 100 & 350 & 350 & 1050 & 1430 & 1430 & 1670 & 1900 \\
Depth (m bgs) & 7 & 5 & 8 & 7.5 & 18.75 & 12.5 & 18.5 & 51 & 19 & 28.5 & 19 \\
\hline
\end{tabular}

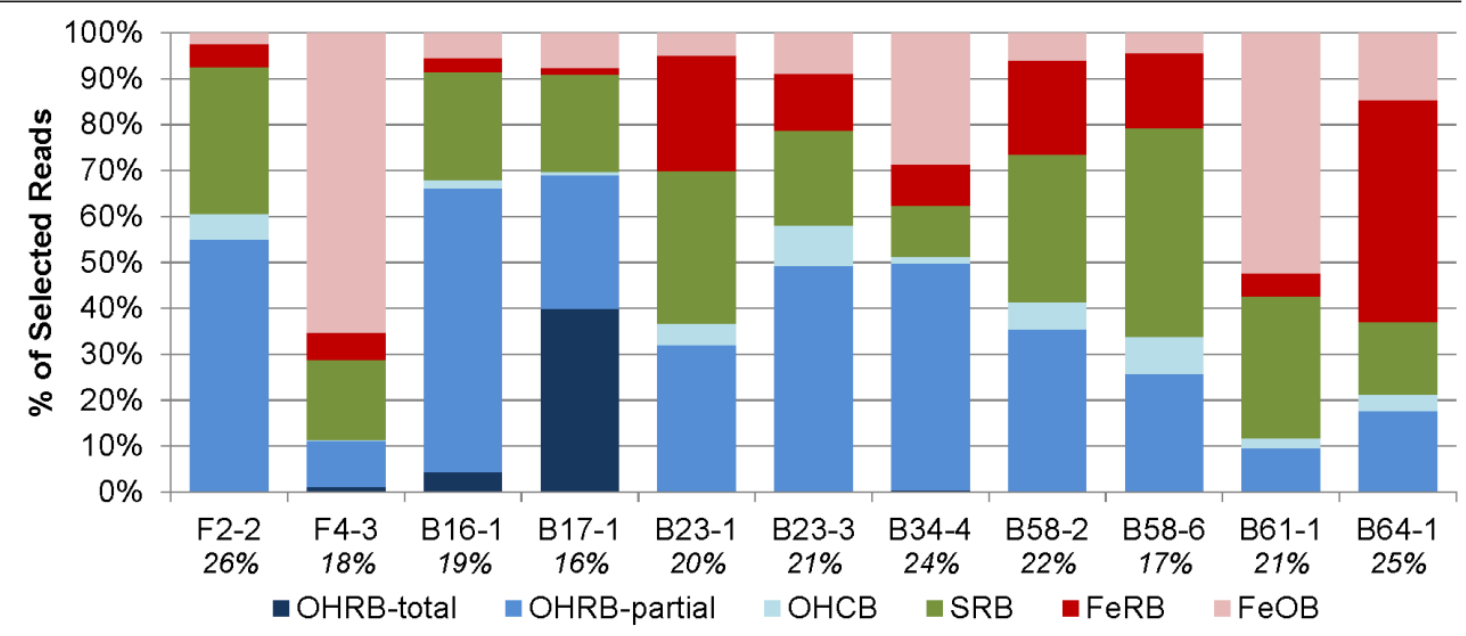

Figure 6: 16S rRNA gene amplicon sequencing results, where the bar plot shows the distribution of the relative abundance of selected reads and the italicized percentage below each column denotes the proportion of the selection to the total number reads in each sample. Distance indicates distance from the source zone.

16S rRNA gene amplicon sequencing yielded information as to the relative abundance of the entire microbial community in each sampled screen. Operational taxonomic units (OTUs) known to represent anoxic redox and degradation functional guilds were included in the analyses, including Organohalide Respiring-Respiring Bacteria (OHRB), Organohalide Cometabolic / Oxidizing Bacteria (OHCB), Sulfate Reducing Bacteria (SRB), Iron Reducing Bacteria (FeRB), and Iron Oxidizing Bacteria (FeOB) (Table S5). OHRB were further divided into the categories partial and 709 total, where OHRB-partial denotes those OTUs with known capability to dechlorinate PCE and 710 TCE to cDCE and OHRB-total denotes those OTUs with known capability to dechlorinate cDCE 711 and VC to ethene. Guilds that were not selected for in depth analysis accounted for approximately 712 three quarters of the reads in each sample and include, for example, fermenting and aerobic 713 bacteria. 
714 Figure 6 shows that the OHRB total and partial guilds combined account for up to $14 \%$ of the total 715 reads in some samples. This portion is consistently greater than that of other guilds, such as SRB, 716 and indicates that organohalide respiration is a significant enough process to support a substantial 717 portion of the total microbial community. Most OHRB OTUs are those with partial degradation 718 capability; the exception to this is screen B17-1, $100 \mathrm{~m}$ from the source zone, where $44 \%$ of the 719 selected OTUs represent bacteria with the capacity to degrade CDCE and VC, with the primary 720 contribution from the genus Dehalogenimonas. However, B17-1 was not analyzed for cerA, so it is 721 not possible to ascertain whether these Dehalogenimonas express this VC $r d h A$ gene. The largest 722 OTUs identified to partially respire chlorinated ethenes are those in the Dehalococcoidales order 723 and Dehalococcoidaceae family that could not be further classified to a family or genus. It is 724 therefore possible that some of these reads could belong to the Dehalococcoides or 725 Dehalogenimonas genera, which were coded as OHRB-total, but were unable to be identified as 726 such.

727 The OHRB guilds are present throughout the plume, and their relative abundances generally 728 decrease with increased distance from the source, which corroborates the trend seen in the specific 729 degrader DNA analyses. These results match well with pyrotag sequencing data from 2014, where 730 Dehalococcoides and Dehalogenimonas were found throughout the plume, and also with specific 731 degrader analyses conducted by GEUS in 2014, where Dehalococcoides was detected, but were 732 below the quantification limit throughout the portion of the plume that is $1050 \mathrm{~m}$ and further from 733 the source (i.e. the sulfate reducing zone and the plume front). It could be that these bacteria were 734 present and active in this area in 2014, but were first definitely quantifiable in 2017 due to the time 735 it may take for the bacteria to establish themselves. Dehalobacter, Desulfitobacterium, and 736 Desulfuromonas, detected in the Microbial Insights analysis in 2017, were not found in the 2017 737 community sequencing analysis. Imfeld et al., 2010 also found that more OHRB genera were 
detectable using taxon specific rather than clone library analysis. In the 2017 sequencing analysis,

739 the only reads assigned to the Peptococcaceae family, which includes both Dehalobacter and Desulfitobacterium, belonged to the SRB Desulfosporosinus meridiei (Robertson et al., 2001), though Dehalobacter was detected in the pyrotag sequencing in 2014 using the same sequence library, Greengenes.

OHCB were detected consistently throughout the plume, though at low relative abundance as compared to the OHRB. Aerobic oxidation of chlorinated ethenes has been documented to occur in what are typically labelled anaerobic conditions that contain as little as $0.1 \mathrm{mg} \mathrm{L}^{-1}$ of dissolved oxygen (Gossett, 2010; Richards et al., 2019). However, all measured concentrations of oxygen below the pyrite oxidation front were an order of magnitude lower than this limit (see Supplementary Information). Additionally, the genes etnE and etnC were not detected by the Microbial Insights QuantArray analysis at any point in the plume, which suggests etheneotrophs implicated in cometabolic aerobic degradation of VC are not active (Liang et al., 2017).

Possible SRB, FeRB, and FeOB containing OTUs are observed in all measured wells. The relative proportion of FeRB in each well has increased to $2 \%-48 \%$ in 2017, as compared to $0 \%-4 \%$ in 2014 , which is consistent with the redox chemical parameters that show less reduced conditions in 2017 as compared to 2014. B64-1 in particular, at $1900 \mathrm{~m}$ from the source zone, exhibits a large relative abundance of FeRB and low relative abundance of OHRB. The low abundance of OHRB is consistent with the lower concentrations of chlorinated ethenes at the plume front, and the higher relative abundance of FeRB is consistent with indications from the redox chemical analyses.

758 Multiple factor analyses at chlorinated ethene contaminated sites have shown that VC reduction and 759 iron reduction are competing processes (Shani et al., 2013), and thus the capability for the microbial community to reduce iron at this section of the plume may inhibit VC reduction. However, it should 761 be noted that FeRB and FeOB are phylogenetically diverse, which renders their identification in the 
Illumina sequencing results more uncertain than for the specialists OHRB and OHCB (Weber et al., 2006). Pyrite oxidation is in general carried out by FeOB (Schippers and Jorgensen, 2002;

Silverman, 1967). While F4-3, which is closest to the surface, and B61-1, which is located at 28.5 mbgs, both have larger selected proportions of FeOB, these bacteria also appear to be more or less well distributed throughout the length and depth of the plume. OTUs purportedly capable of sulfate reduction were identified in all wells; there was no distinct trend at B34-4, in the sulfate reducing zone. Some SRB are facultative and can use electron acceptors other than sulfate, which could explain their ubiquitous distribution in the plume (Castro et al., 2000). Sulfate reduction has been shown to inhibit organohalide respiration (Berggren et al., 2013; Murray et al., 2019), but has also in some cases stimulated dechlorination (Harkness et al., 2012; Murray, 2019). The two processes, sulfate reduction and DCE dechlorination, have been documented to occur concurrently by geochemical and microbial community analysis in a constructed wetland, which is similar to the Rødekro plume in that it is an anoxic, sandy environment (Imfeld et al., 2010). Microbial community interactions are complex; metabolic complementarity in the microbial community and the functional capabilities of the organisms that support OHRB may play an important role in stimulation or inhibition of dechlorination (Hug et al., 2012; Murray, 2019; Pérez-De-Mora et al., 2014; Wang et al., 2019).

The microbial analyses in general show that there is the possibility for anaerobic reductive, aerobic metabolic, or co-metabolic degradation of chlorinated ethenes throughout the plume, including at $1050 \mathrm{~m}$ from the source in the sulfate reducing zone. The capability for complete reduction is strongest directly downgradient of the source zone, where the genes $v c r A, b v c A$, and $\operatorname{cer} A$ are detected, and weakest at the plume front, where FeRB are present in the highest relative abundance. 
785 The information provided by the physical, chemical, isotopic, and microbial lines of evidence can 786 be combined to create one comprehensive, holistic picture of the fate and transport of chlorinated 787 ethenes (Badin et al., 2016; Courbet et al., 2011; Hunkeler et al., 2011; Nijenhuis et al., 2018, 788 2007), as was done in the Rødekro plume. The overview of the degradation mechanisms cannot 789 only be elucidated spatially, but also temporally when the results from all three sampling campaigns 790 are analyzed collectively, as depicted in Figure 7. Figure 7-2017 includes all new information from 791 the current study. Figure 7-2006 and Figure 7-2014 are re-depictions of data presented in Hunkeler 792 et al., 2011 and Badin et al., 2016, respectively. The colored boxes in Figure 7 coarsely delineate 793 various areas of the plume with common characteristics. 


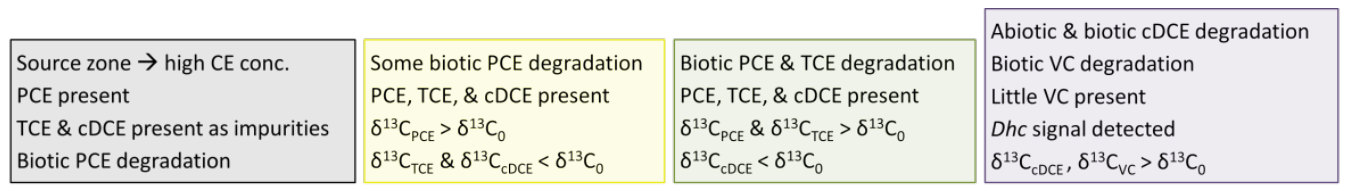
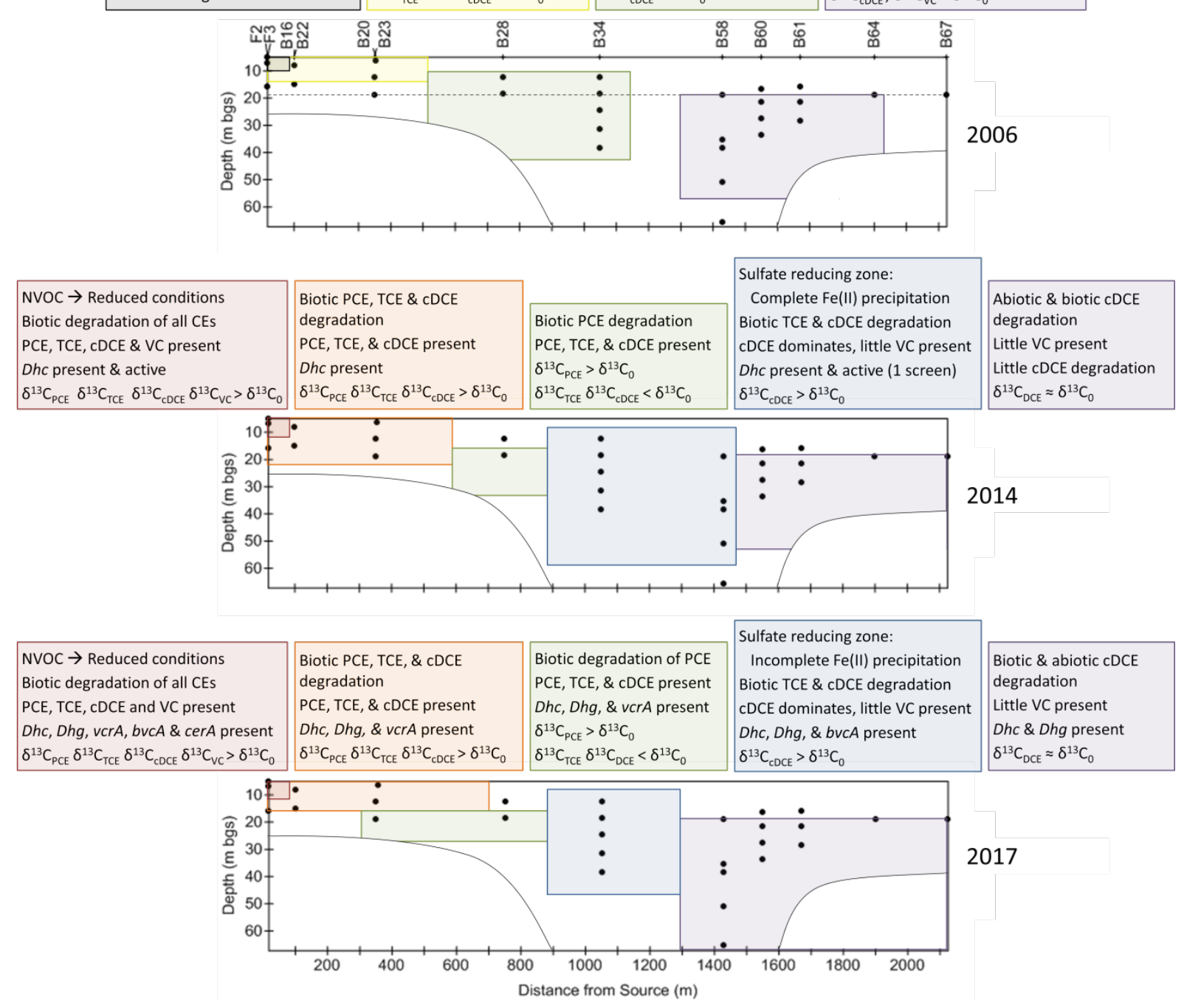

795 Figure 7: Summary of conditions and degradation mechanisms present in the plume during each

796 major sampling campaign. The colored boxes coarsely delineate zones in the plume where different

797 conditions/processes occur and the relevant parameters found in these zones. Parameters not

798 discussed in the boxes indicate both not measured and not detected. $\mathrm{CE}=$ chlorinated ethene, $\mathrm{Dhc}=$

799 Dehalococcoides spp., Dhg = Dehalogenimonas spp.

800 The effect of the source zone thermal remediation on the plume is the most marked change between

8012006 and 2014. In 2006, chlorinated ethene concentrations were very high immediately 
downgradient from the source zone depicted in Figure 7 as the black box. After the remediation, 803 this area became reduced due to the released DOC, biotic degradation began to take place, and the 804 chlorinated ethene concentrations decreased by 85\%. Biotic degradation was also enhanced in the red and orange boxes, and Dehalococcoides was present and active here in 2014, unlike before the remediation event. The DOC release also reduced conditions further from the source, and a sulfate 807 reducing zone, depicted in blue, was identified in 2014. Isotopic signatures provided evidence that 808 decreases in TCE and cDCE concentrations were indeed due to degradation. Conditions in this reduced zone were favorable for biotic degradation, though Dehalococcoides was only present, and at low abundance and activity, at one point between well B34 and the plume front in 2014. This is 811 similar to results from 2006, where a Dehalococcoides signal, below the quantification limit, was 812 observed in two screens between well B34 and the plume front.

813 The enhanced degradation continued to be apparent in 2017, and the evolution of the plume can be 814 determined using the multiple lines of evidence. Despite that active Dehalococcoides populations 815 were not detected in 2017, the microbial line of evidence overall more firmly indicates biotic degradation than in previous sampling campaigns as the specific degraders Dehalococcoides and Dehalogenimonas and VC rdhA genes were detected throughout the plume in 2017, with the exception that no VC $r d h A$ genes were detected near the plume front. This is a marked change from 2014, where Dehalococcoides was principally located within the first $350 \mathrm{~m}$ from the source, and 821 become more enriched in some key locations, though isotopic evidence of degradation is found in 822 the same locations in 2017 as in 2014.

823 In the area immediately downgradient from the source, indicated by the red boxes, all chlorinated 824 ethenes were detected in both 2014 and 2017. The $\delta^{13} \mathrm{C}$ were enriched for all chlorinated ethenes in 
2017 and indicate that TCE and cDCE are degradation products, rather than impurities, as was the case in 2006. The local anoxic areas suitable for anaerobic cDCE reduction in the mixed redox zone were still present in 2017. Unlike in 2014, however, all three analyzed VC $r d h A$ genes were detected. The isotopic evidence combined with expression of these genes by Dehalococcoides and Dehalogenimonas is a strong indication that VC is biotically degraded in this area.

The mixed zone extends past the red boxes in both 2014 and 2017, though it has decreased in size, and dual C-Cl isotope slopes indicate that when PCE and TCE are degraded in the red, orange, and green boxes, the mechanism is anaerobic reductive dechlorination. Thus, biotic degradation still occurs here as in 2014; however, the $\delta^{13} \mathrm{C}$ values for TCE show that TCE is no longer degraded in the deeper part of the plume at $350 \mathrm{~m}$ downgradient from the source, represented by the change in shape of the green box. The rate at which PCE is degraded between the orange and the green box is three times higher than in 2014, yet in both years, PCE is fully converted to daughter compounds before reaching the blue box. VC was detected in neither the orange nor the green boxes in both years. In 2017, vcrA was detected, which indicates that VC is used an electron acceptor and degradation past cDCE may occur in this area. Community sequencing data in 2017 also show that 840 bacteria that may be capable of complete dechlorination comprise $44 \%$ of the community in B17-1, 841 in the orange box.

842 The sulfate reducing zone, depicted as the blue box, is still present in 2017, though it is less reduced 843 than in 2014 and has decreased in size. The redox conditions appear to slowly be returning to the 844 conditions prior to the remediation event, though the impact after one decade is still strong and 845 apparent; the presence of Dehalococcoides, Dehalogenimonas, and bvcA indicate that biotic 846 degradation occurs in this area. The enriched $\delta^{13} \mathrm{C}$ values for cDCE document that it is degraded 847 here, however because $\mathrm{Cl}$ isotopic ratios for CDCE could not be obtained in 2017, dual isotope plots 
are not available to assess the degradation pathway. Dual isotope slopes for cDCE from the previous sampling campaigns suggest the mechanism could be anaerobic reductive dechlorination and/or abiotic degradation by iron minerals. The shortest estimated half-lives for cDCE in this area of the plume are 23 and 10 years for 2014 and 2017, respectively, and the conditions favorable for anaerobic reductive dechlorination would need to be present for at least a kilometer to reduce the concentration of cDCE to half of its 2014 level. The slow rate is insufficient to completely reduce cDCE within the blue box, which is disappearing, though this may be compensated for by increased degradation prior to the chlorinated ethenes entering this reduced zone. The evolution of this dynamic can be investigated in future sampling campaigns. significantly less than would be expected from groundwater transport. While it may be that the clay lens that begins $1500 \mathrm{~m}$ from the source influences the contaminant transport, the stationary nature of the plume is most likely evidence that the cDCE that enters the purple box undergoes a 861 destructive process. VC concentrations in the purple box in 2017 are low, such that measurement of 862 the isotopic signature was not possible. However, in 2006 both cDCE and VC $\delta^{13} \mathrm{C}$ values were 863 enriched in this part of the plume, documenting that transformation of both compounds occurred. 864 The low concentrations of VC measured in 2017 may be due to abiotic degradation of cDCE, where 865 VC is not produced or is produced in small amounts (Lee and Batchelor, 2002a), or may be because biotic cDCE degradation is the rate limiting step. Though well B76 was deemed to be on the plume

867 fringe rather than on the flowline (see SI), the $\mathrm{VC} \delta^{13} \mathrm{C}$ ratio in well $\mathrm{B} 76$ shows significant 868 enrichment, which is evidence that VC degradation occurs at this location. This point may only 869 provide insight to the local conditions at well B76, or may be representative of this area of the 870 plume, where VC concentrations are too low to measure isotopic signals. cDCE isotopic analyses 871 along the plume centerline do not document that degradation of cDCE occurs in this area of the 
872

plume, as the $\delta^{13} \mathrm{C}$ values for cDCE were nearly the same as the $\delta^{13} \mathrm{C}_{0}$. It is possible that cDCE here is degraded via a mechanism/bacterial strain that does not influence the $\delta^{13} \mathrm{C}$ ratios, though it is expected that during future sampling campaigns, the enriched cDCE detected at well B34 in 2014 would be detected in well B58 the purple box. Dehalococcoides and Dehalogenimonas were detected in the purple box, though no VC reductase genes were detected. Non-detection of the VC reductase genes does not necessarily indicate that VC reduction does not occur, as lower chlorinated ethene concentrations in total would provide fewer electron acceptors for this bacterial guild, and thus these bacteria would be present in smaller quantities and are possibly below detection. It is also possible that VC respiration in this part of the plume is facilitated by currently unidentified species or genes or by microaerophilic or anaerobic oxidation (Bradley et al., 1998; Liang et al., 2017; Smits et al., 2011).

Chlorinated ethenes can be degraded abiotically by pyrite to become acetylene (Lee and Batchelor, 2002a). Although abiotic reduction by iron sulfide minerals is well documented in laboratory experiments, the degradation products are easily converted to readily biodegradable compounds, so it is difficult to document in situ (Liang et al., 2009). Additionally, it is not well investigated, especially in comparison to biotic degradation (He et al., 2015). The stable iron sulfide mineral pyrite is commonly found in sandy Danish aquifers, but it is also likely that other iron sulfide minerals are present, such as mackinawite or amorphous FeS precipitate as a result of sulfate reduction. Both cDCE and VC have been shown to be reactive with a number of iron minerals, such as pyrite and green rust (Lee and Batchelor, 2002a, 2002b), however there are conflicting results on whether cDCE degradation can be mediated by mackinawite (Hyun and Hayes, 2015; Jeong et al., 2011). While it is possible that abiotic reduction of chlorinated ethenes does occur in the aquifer based on the presence of iron-sulfide minerals and dual C-Cl isotope slopes, it is not possible to establish that any particular mechanism is responsible. Information provided by the different lines 
of evidence are not necessarily mutually exclusive - the detection of specific degraders does not exclude the possibility that abiotic degradation also occurs. From 1450 m downgradient from the source to the plume front, chlorinated ethenes do undergo a destructive process, and it is likely that some combination of abiotic and biotic degradation of cDCE and VC occurs here.

\section{Perspectives on Rødekro plume evolution}

The removal of the majority of the source in 2006 has still not resulted in detachment of the plume in Rødekro, as was also documented in 2014. While the plume is growing in the longitudinal direction, it is at a very slow rate; natural destructive processes are currently able to compensate for chlorinated ethene transport in the aquifer and the plume has remained at more or less steady state after the remediation event. However, the aquifer redox conditions, which were altered by the DOC release, are returning to their natural state prior to the source remediation.

The microbial response to the DOC release from the thermal remediation indicates that if remediation were to be applied to the plume, it would be a good candidate for biostimulation. Furthermore, the relatively high pore water velocity would ensure quick, widespread donor distribution. Nevertheless, the DOC concentrations in the wells immediately downgradient from the source still match the levels recorded in 2014 and there is more evidence of biotic degradation than in previous sampling campaigns. The degree to which the destructive processes occur is sufficient to contain the contamination and remediation is not necessary at present. This is fortunate, as despite the positive microbial response to the DOC release, a plume of such depth and extent is still difficult to remediate, and monitored natural attenuation is a more efficient use of resources.

While the future of the plume is impossible to foretell, based on the response to the remediation event over the past decade, it is likely that the natural attenuation processes in the plume will be sustained for some time in the future. The reduced conditions in the plume required substantial 
919 input to change, but appear to be sustained longer than was originally predicted. This may be due to 920 further production of electron donor, hydrogen, from fermentation of endogenous biomass decay 921 products as the activity of the microbial community decreases (Adamson and Newell, 2009; Sleep 922 et al., 2005). Monitored natural attenuation in the plume will likely remain a sufficient approach 923 considering that some biotic degradation was documented to occur prior to the remediation event 924 and that, post remediation, there is much less contaminant mass entering the plume. The long-term 925 evaluation of the plume response to the source remediation event gives a broader perspective to management of the risk posed by contaminated sites.

\section{Conclusion}

928 Continued, in-depth study of the Rødekro plume has produced an extensive dataset from multiple 929 lines of evidence that encompasses more than a decade of plume evolution. This dataset allows for a 930 unique, deep dive into the processes and degradation mechanisms that impact the fate and transport 931 of the chlorinated ethenes. The various scales and scopes of the site investigation allow for us to not 932 only make conclusions about the plume as a whole, but also to investigate processes on a smaller 933 scale and over time. For example, the delayed response to the 2014 redox changes can be identified 934 by the appearance of quantifiable amounts of bacteria and $r d h A$ genes in 2017. The estimation of 935 local degradation rates yields information about the fate of the contaminants and also adds to the 936 library of degradation rates available in the literature for risk assessment (Ottosen et al., 2019). 937 Furthermore, the dataset provides the opportunity to reassess old data with new knowledge, such as 938 estimation of degradation rates, dual C-Cl isotope slopes, and discovery of new $r d h A$ genes.

939 However, there are still limitations to what can be achieved with the extensive dataset. The lines of 940 evidence approach is successful for definite identification that the chlorinated ethenes undergo a 941 destructive process, but when two lines of evidence indicate different mechanisms, it is still problematic to ascertain the distinct mechanism(s) responsible for the contaminant degradation. As 
was discussed in Badin et al., 2016, sites with complex iron geochemistry are not well explored.

944 More research on these systems could further our understanding of the interplay between biotic and 945 abiotic degradation. Additionally, the field of dual C-Cl isotope analysis is relatively new and is still 946 evolving, as Cl isotope analysis has only become more reliable in recent years (Elsner et al., 2012).

947 While dual C-Cl isotope slopes can provide valuable information in the assessment of which 948 degradation mechanism(s) occur, further research is required to combine slope trends and 949 degradation by specific bacteria strains, and to evaluate how simultaneously occurring degradation 950 pathways influence these trends.

951 The extensive temporal and spatial analysis of the Rødekro plume allows for tracking the evolution 952 of the plume and the lasting impact of the source remediation. The plume itself is complex 953 throughout its length, and the multiple lines of evidence approach is essential to elucidate the 954 primary degradation mechanisms in its various areas. Each line of evidence can be used to 955 strengthen the others, and the information they give in combination is greater than the sum of their 956 parts.

\section{Acknowledgements}

958 We gratefully acknowledge the Region of Southern Denmark, Denmark for the opportunity to 959 sample at the site and for partial financing of the sampling campaign. Arwos, Denmark is 960 acknowledged for the remainder of the funding for the sampling campaign. DTU is acknowledged 961 for PhD student funding. We further acknowledge Lone Dissing (Region of Southern Denmark) for 962 feedback on the manuscript and Lone Dissing and Niels Just (Region of Southern Denmark) for 963 their contributions to planning and executing the campaign. Jesper L. Gregersen and Bjarke Foss 964 (Region of Southern Denmark) are acknowledged for their hard work in the field. Aikaterini 965 Tsitonaki (Orbicon) is acknowledged for her feedback on the manuscript, and Aikaterini Tsitonaki 966 and Kresten Andersen (Orbicon) are acknowledged for their involvement in preparing and 
967 executing the sampling campaign. Aline Adler and Emmanuelle Rohrbach (EPFL) are

968 acknowledged for their work with sequencing and bioinformatics. Britta Drude (DTU) is

969 acknowledged for her hard work in the field and laboratory and for her contributions to the data

970 treatment and analysis in her MSc project. Lastly, we acknowledge two anonymous reviewers for

971 their constructive comments and help improving the quality of the manuscript.

972 


\section{References}

974 Abe, Y., Aravena, R., Zopfi, J., Shouakar-Stash, O., Cox, E., Roberts, J.D., Hunkeler, D., 2009.

Carbon and chlorine isotope fractionation during aerobic oxidation and reductive dechlorination of vinyl chloride and cis-1, 2-dichloroethene. Environ. Sci. Technol. 43, 101107. https://doi.org/10.1021/es801759k

978

979

980

Abe, Y., Hunkeler, D., 2006. Does the Rayleigh Equation Apply to Evaluate Field Isotope Data in Contaminant Hydrogeology? Environ. Sci. Technol. 40, 1588-1596. https://doi.org/10.1021/es051128p

Adamson, D.T., Newell, C.J., 2009. Support of source zone bioremediation through endogenous biomass decay and electron donor recycling. Bioremediat. J. 13, 29-40. https://doi.org/10.1080/10889860802690539

Aeppli, C., Hofstetter, T.B., Amaral, H.I.F., Kipfer, R., Schwarzenbach, R.P., Berg, M., 2010. Quantifying In Situ Transformation Rates of Chlorinated Ethenes by Combining CompoundSpecific Stable Isotope Analysis, Groundwater Dating, And Carbon Isotope Mass Balances. Environ. Sci. Technol. 44, 3705-3711.

Appelo, C.A.J., Postma, D., 2005. 3 Flow and Transport. In: Geochemistry, Groundwater and Pollution, 2nd ed. CRC Press, pp. 63-118.

Audí-Miró, C., Cretnik, S., Otero, N., Palau, J., Shouakar-Stash, O., Soler, A., Elsner, M., 2013. Cl and $\mathrm{C}$ isotope analysis to assess the effectiveness of chlorinated ethene degradation by zerovalent iron: Evidence from dual element and product isotope values. Appl. Geochemistry 32, 175-183. https://doi.org/10.1016/j.apgeochem.2012.08.025

Audí-Miró, C., Cretnik, S., Torrentó, C., Rosell, M., Shouakar-Stash, O., Otero, N., Palau, J., 
Elsner, M., Soler, A., 2015. C, Cl and H compound-specific isotope analysis to assess natural versus $\mathrm{Fe}(0)$ barrier-induced degradation of chlorinated ethenes at a contaminated site. J. Hazard. Mater. 299, 747-754. https://doi.org/10.1016/j.jhazmat.2015.06.052

Badin, A., Broholm, M.M., Jacobsen, C.S., Palau, J., Dennis, P., Hunkeler, D., 2016. Identification of abiotic and biotic reductive dechlorination in a chlorinated ethene plume after thermal source remediation by means of isotopic and molecular biology tools. J. Contam. Hydrol. 192, 1-19. https://doi.org/10.1016/j.jconhyd.2016.05.003

Badin, A., Buttet, G., Maillard, J., Holliger, C., Hunkeler, D., 2014. Multiple dual C-cl isotope patterns associated with reductive dechlorination of tetrachloroethene. Environ. Sci. Technol. 48, 9179-86. https://doi.org/10.1021/es500822d

Bælum, J., Chambon, J.C., Scheutz, C., Binning, P.J., Laier, T., Bjerg, P.L., Jacobsen, C.S., 2013. A conceptual model linking functional gene expression and reductive dechlorination rates of chlorinated ethenes in clay rich groundwater sediment. Water Res. 47, 2467-2478. https://doi.org/10.1016/j.watres.2013.02.016

Berggren, D.R. V, Marshall, I.P.G., Azizian, M.F., Spormann, A.M., Semprini, L., 2013. Effects of sulfate reduction on the bacterial community and kinetic parameters of a dechlorinating culture under chemostat growth conditions. Environ. Sci. Technol. 47, 1879-1886. https://doi.org/10.1021/es304244z

Blazquez-Pali, N., Rosell, M., Varias, J., Bosch, M., Soler, A., Vicent, T., Marco-Urrea, E., et al., 2019. Multi-method assessment of the intrinsic biodegradation potential of an aquifer contaminated with chlorinated ethenes at an industrial area in Barcelona (Spain). Environmental Pollution 244, 165-173. doi:https://doi.org/10.1016/j.envpol.2018.10.013. 
1018 1019 1020 1021 1022 1023 1024 1025 1026 1027 1028 1029 1030 1031 1032 1033 1034 1035 1036 1037 1038 1039

Bloom, Y., Aravena, R., Hunkeler, D., Edwards, E., Frape, S.K., 2000. Carbon isotope fractionation during microbial dechlorination of trichloroethene, cis-1,2-dichloroethene, and vinyl chloride: Implications for assessment of natural attenuation. Environ. Sci. Technol. 34, 2768-2772. https://doi.org/10.1021/es991179k

Bradley, P.M., 2000. Microbial degradation of chloroethenes in groundwater systems. Hydrogeol. J. 8, 104-111. https://doi.org/10.1007/s100400050011

Bradley, P.M., Chapelle, F.H., 2000. Aerobic microbial mineralization of dichloroethene as sole carbon substrate. Environ. Sci. Technol. 34, 221-223. https://doi.org/10.1021/es990785c

Bradley, P.M., Chapelle, F.H., Lovley, D.R., 1998. Humic Acids as Electron Acceptors for Anaerobic Microbial Oxidation of Vinyl Chloride and Dichloroethene. Appl. Environ. Microbiol. 64, 3102-3105.

Braeckevelt, M., Fischer, A., Kästner, M., 2012. Field applicability of Compound-Specific Isotope Analysis (CSIA) for characterization and quantification of in situ contaminant degradation in aquifers. Appl. Microbiol. Biotechnol. 94, 1401-1421. https://doi.org/10.1007/s00253-0124077-1

Buchner, D., Behrens, S., Laskov, C., Haderlein, S.B., 2015. Resiliency of Stable Isotope Fractionation $(\delta 13 \mathrm{C}$ and $\delta 37 \mathrm{Cl})$ of Trichloroethene to Bacterial Growth Physiology and Expression of Key Enzymes. Environ. Sci. Technol. 49, 13230-13237. https://doi.org/10.1021/acs.est.5b02918

Castro, H.F., Williams, N.H., Ogram, A., 2000. Phylogeny of sulfate-reducing bacteria 1. FEMS Microbiol. Ecol. 31.

Courbet, C., Rivière, A., Jeannottat, S., Rinaldi, S., Hunkeler, D., Bendjoudi, H., De Marsily, G., 
1040

1041

1042

1043

1044

1045

1046

1047

1048

1049

1050

1051

1052

1053

1054

1055

1056

1057

1058

1059

1060

1061

2011. Complementing approaches to demonstrate chlorinated solvent biodegradation in a complex pollution plume: Mass balance, PCR and compound-specific stable isotope analysis. J. Contam. Hydrol. 126, 315-329. https://doi.org/10.1016/j.jconhyd.2011.08.009

Cretnik, S., Bernstein, A., Shouakar-stash, O., Löffler, F., Elsner, M., 2014. Chlorine Isotope Effects from Isotope Ratio Mass Spectrometry Suggest Intramolecular C-Cl Bond Competition in Trichloroethene (TCE) Reductive Dehalogenation 6450-6473. https://doi.org/10.3390/molecules19056450

Cretnik, S., Thoreson, K. a., Bernstein, A., Ebert, K., Buchner, D., Laskov, C., Haderlein, S., Shouakar-Stash, O., Kliegman, S., McNeill, K., Elsner, M., 2013. Reductive dechlorination of TCE by chemical model systems in comparison to dehalogenating bacteria: Insights from dual element isotope analysis (13C/12C, 37Cl/35Cl). Environ. Sci. Technol. 47, 6855-6863. https://doi.org/10.1021/es400107n

Culpepper, J.D., Scherer, M.M., Robinson, T.C., Neumann, A., Cwiertny, D., Latta, D.E., 2018. Reduction of PCE and TCE by magnetite revisited. Environ. Sci. Process. Impacts 20, 12991490. https://doi.org/10.1039/c8em00286j

Cwiertny, D.M., Scherer, M.M., 2010. Chapter 2: Chlorinated solvent Chemistry: Structures, Nomenclature, and Properties, in: In Situ Remediation of Chlorinated Solvent Plumes. pp. 2938. https://doi.org/10.1007/978-1-4419-1401-9

Damgaard, I., Bjerg, P.L., Bælum, J., Scheutz, C., Hunkeler, D., Jacobsen, C.S., Tuxen, N., Broholm, M.M., 2013. Identification of chlorinated solvents degradation zones in clay till by high resolution chemical, microbial and compound specific isotope analysis. J. Contam. Hydrol. 146, 37-50. https://doi.org/10.1016/j.jconhyd.2012.11.010 
Doğan-Subaşı, E., Elsner, M., Qiu, S., Cretnik, S., Atashgahi, S., Shouakar-Stash, O., Boon, N., Dejonghe, W., Bastiaens, L., 2017. Contrasting dual (C, Cl) isotope fractionation offers potential to distinguish reductive chloroethene transformation from breakdown by permanganate. Sci. Total Environ. 596-597, 169-177. https://doi.org/10.1016/j.scitotenv.2017.03.292

Elsner, M., Chartrand, M., Vanstone, N., Couloume, G.L., Lollar, B.S., 2008. Identifying abiotic chlorinated ethene degradation: Characteristic isotope patterns in reaction products with nanoscale zero-valent iron. Environ. Sci. Technol. 42, 5963-5970. https://doi.org/10.1021/es8001986

Elsner, M., Jochmann, M.A., Hofstetter, T.B., Hunkeler, D., Bernstein, A., Schmidt, T.C., Schimmelmann, A., 2012. Current challenges in compound-specific stable isotope analysis of environmental organic contaminants. Anal. Bioanal. Chem. 403, 2471-2491. https://doi.org/10.1007/s00216-011-5683-y

Friis, A.K., Albrechtsen, H.J., Heron, G., Bjerg, P.L., 2005. Redox processes and release of organic matter after thermal treatment of a TCE-contaminated aquifer. Environ. Sci. Technol. 39, 5787 5795.

Gafni, A., Lihl, C., Gelman, F., Elsner, M., Bernstein, A., 2018. $\delta 13 \mathrm{C}$ and $\delta 37 \mathrm{Cl}$ Isotope Fractionation to Characterize Aerobic vs Anaerobic Degradation of Trichloroethylene. Environ. Sci. Technol. Lett. 5, 202-208. https://doi.org/10.1021/acs.estlett.8b00100

Gossett, J.M., 2010. Sustained Aerobic Oxidation of Vinyl Chloride at Low Oxygen Concentrations. Environ. Sci. Technol. 44, 1405-1411.

Griebler, C., Lueders, T., Mu, H.Z., 2009. Microbial biodiversity in groundwater ecosystems 649- 
1085

1086

1087

1088

1089

1090

1091

1092

1093

1094

1095

1096

1097

1098

1099

1100

1101

1102

1103

1104

1105

Harkness, M., Fisher, A., Lee, M.D., MacK, E.E., Payne, J.A., Dworatzek, S., Roberts, J., Acheson, C., Herrmann, R., Possolo, A., 2012. Use of statistical tools to evaluate the reductive dechlorination of high levels of TCE in microcosm studies. J. Contam. Hydrol. 131, 100-118. https://doi.org/10.1016/j.jconhyd.2012.01.011

He, Y.T., Wilson, J.T., Wilkin, R.T., 2015. Review of Abiotic Degradation of Chlorinated Solvents by Reactive Iron Minerals in Aquifers. Groundw. Monit. Remediat. 35, 57-75. https://doi.org/10.1111/gwmr.12111

Holliger, C., Schraa, G., Stams, A.J.M., Zehnder, A.J.B., 1993. A highly purified enrichment culture couples the reductive dechlorination of tetrachloroethene to growth. Appl. Environ. Microbiol. 59, 2991-2997.

Hug, L. a, Maphosa, F., Leys, D., Löffler, F.E., Smidt, H., Edwards, E. a, Adrian, L., 2013. Overview of organohalide-respiring bacteria and a proposal for a classification system for reductive dehalogenases. Philos. Trans. R. Soc. Lond. B. Biol. Sci. https://doi.org/10.1098/rstb.2012.0322

Hug, L.A., Beiko, R.G., Rowe, A.R., Richardson, R.E., Edwards, E.A., 2012. Comparative metagenomics of three Dehalococcoides-containing enrichment cultures: the role of the nondechlorinating community. BMC Genomics 13. https://doi.org/10.1186/1471-2164-13-327

Hunkeler, D., Abe, Y., Broholm, M.M., Jeannottat, S., Westergaard, C., Jacobsen, C.S., Aravena, R., Bjerg, P.L., 2011. Assessing chlorinated ethene degradation in a large scale contaminant plume by dual carbon-chlorine isotope analysis and quantitative PCR. J. Contam. Hydrol. 119, 69-79. https://doi.org/10.1016/j.jconhyd.2010.09.009 
1106 Hunkeler, D., Van Breukelen, B.M., Elsner, M., 2009. Modeling chlorine isotope trends during sequential transformation of chlorinated ethenes. Environ. Sci. Technol. 43, 6750-6756. https://doi.org/10.1021/es900579z

1109

1110

1111

1112

1113

1114

1115

1116

Hyun, S.P., Hayes, K.F., 2015. Abiotic reductive dechlorination of cis-DCE by ferrous monosulfide mackinawite. Environ. Sci. Pollut. Res. 22, 16463-16474. https://doi.org/10.1007/s11356-015$5033-2$

Imfeld, G., Aragonés, C.E., Fetzer, I., Mészáros, É., Zeiger, S., Nijenhuis, I., Nikolausz, M., Delerce, S., Richnow, H.H., 2010. Characterization of microbial communities in the aqueous phase of a constructed model wetland treating 1,2-dichloroethene-contaminated groundwater. FEMS Microbiol. Ecol. 72, 74-88. https://doi.org/10.1111/j.1574-6941.2009.00825.x

Imfeld, G., Nijenhuis, I., Nikolausz, M., Zeiger, S., Paschke, H., Drangmeister, J., Grossmann, J., Richnow, H.H., Weber, S., 2008. Assessment of in situ degradation of chlorinated ethenes and bacterial community structure in a complex contaminated groundwater system. Water Res. 42, 871-882. https://doi.org/10.1016/j.watres.2007.08.035

Imfeld, G., Pieper, H., Shani, N., Rossi, P., Nikolausz, M., Nijenhuis, I., Paschke, H., Weiss, H., Richnow, H.H., 2011. Characterization of Groundwater Microbial Communities, Dechlorinating Bacteria, and In Situ Biodegradation of Chloroethenes Along a Vertical Gradient. Water, Air, Soil Pollut. 221, 107-122. https://doi.org/10.1007/s11270-011-0774-0

Jeong, H.Y., Anantharaman, K., Han, Y.S., Hayes, K.F., 2011. Abiotic reductive dechlorination of cis-dichloroethylene by Fe species formed during iron- or sulfate-reduction. Environ. Sci. Technol. 45, 5186-5194. https://doi.org/10.1021/es104387w

Kret, E., Kiecak, A., Malina, G., Nijenhuis, I., Postawa, A., 2015. Identification of TCE and PCE 
sorption and biodegradation parameters in a sandy aquifer for fate and transport modelling: batch and column studies. Environ. Sci. Pollut. Res. 22, 9877-9888. https://doi.org/10.1007/s11356-015-4156-9

Kuder, T., Van Breukelen, B.M., Vanderford, M., Philp, P., 2013. 3D-CSIA: Carbon, chlorine, and hydrogen isotope fractionation in transformation of TCE to ethene by a Dehalococcoides culture. Environ. Sci. Technol. 47, 9668-9677. https://doi.org/10.1021/es400463p

Lee, W., Batchelor, B., 2002a. Abiotic Reductive Dechlorination of Chlorinated Ethylenes by IronBearing Soil Minerals. 1. Pyrite and Magnetite. Environ. Sci. Technol. 36, 5147-5154.

Lee, W., Batchelor, B., 2002b. Abiotic reductive dechlorination of chlorinated ethylenes by ironbearing soil minerals. 2. Green rust. Environ. Sci. Technol. 36, 5348-5354. https://doi.org/10.1021/es0258374

Liang, X., Paul Philp, R., Butler, E.C., 2009. Kinetic and isotope analyses of tetrachloroethylene and trichloroethylene degradation by model Fe(II)-bearing minerals. Chemosphere 75, 63-69. https://doi.org/10.1016/j.chemosphere.2008.11.042

Liang, Y., Liu, X., Singletary, M.A., Wang, K., Mattes, T.E., 2017. Relationships between the Abundance and Expression of Functional Genes from Vinyl Chloride (VC)-Degrading Bacteria and Geochemical Parameters at VC-Contaminated Sites. Environ. Sci. Technol. 51, 12164-12174. https://doi.org/10.1021/acs.est.7b03521

Lihl, C., Douglas, L.M., Franke, S., Perez-de-Mora, A., Meyer, A.H., Daubmeier, M., Edwards, E.A., Nijenhuis, I., Lollar, B.S., Elsner, M., 2019. Mechanistic Dichotomy in Bacterial Trichloroethene Dechlorination Revealed by Carbon and Chlorine Isotope Effects. Environ. Sci. Technol. 53, 4245-4254. https://doi.org/10.1021/acs.est.8b06643 
1150 Löffler, F.E., Yan, J., Ritalahti, K.M., Adrian, L., Edwards, E.A., Konstantinidis, K.T., Müller, J.A., 1151 Fullerton, H., Zinder, S.H., Spormann, A.M., 2013. Dehalococcoides mccartyi gen. nov., sp. https://doi.org/10.1099/ijs.0.034926-0

Lollar, B.S., Slater, G.F., Sleep, B., Witt, M., Klecka, G.M., Harness, M., Spivack, J., 2001. Stable

McDonald, D., Price, M.N., Goodrich, J., Nawrocki, E.P., Desantis, T.Z., Probst, A., Andersen,

Morrill, P.L., Lacrampe-Couloume, G., Slater, G.F., Sleep, B.E., Edwards, E.A., McMaster, M.L., Major, D.W., Lollar, B.S., 2005. Quantifying chlorinated ethene degradation during reductive dechlorination at Kelly AFB using stable carbon isotopes. J. Contam. Hydrol. 76, 279-293. https://doi.org/10.1016/j.jconhyd.2004.11.002

Murray, A., Maillard, J., Jin, B., Broholm, M., Holliger, C., Rolle, M., 2019. A modeling approach integrating microbial activity, mass transfer, and geochemical processes to interpret biological 

assays: An example for PCE degradation in a multi-phase batch setup (under review). Water Res. 160, 484-496. https://doi.org/10.1016/j.watres.2019.05.087

Murray, A.M., 2019. Impact of the microbial community on chlorinated ethene degradation: laboratory, modeling, and field investigation. Technical University of Denmark.

Nawrocki, E.P., Eddy, S.R., 2013. Infernal 1.1: 100-fold faster RNA homology searches. Bioinformatics 29, 2933-2935. https://doi.org/10.1093/bioinformatics/btt509

Nazaroff, W.W., Alvarez-Cohen, L., 2001. Environmental Engineering Science. John Wiley \& Sons.

Nijenhuis, I., Nikolausz, M., Koth, A., Felfoldi, T., Weiss, H., Drangmeister, J., Großmann, J., Kastner, M., Richnow, H., 2007. Assessment of the natural attenuation of chlorinated ethenes in an anaerobic contaminated aquifer in the Bitterfeld / Wolfen area using stable isotope techniques, microcosm studies and molecular biomarkers. Chemos 67, 300-311. https://doi.org/10.1016/j.chemosphere.2006.09.084

Nijenhuis, I., Stollberg, R., Lechner, U., 2018. Anaerobic microbial dehalogenation and its key players in the contaminated Bitterfeld-Wolfen megasite. FEMS Microbiol. Ecol. 94. https://doi.org/10.1093/femsec/fiy012

Ottosen, C.B., Murray, A.M., Broholm, M.M., Bjerg, P.L., 2019. In Situ Quantification of Degradation Is Needed for Reliable Risk Assessments and Site-Specific Monitored Natural Attenuation. Environ. Sci. Technol. 53, 1-3. https://doi.org/10.1021/acs.est.8b06630

Paes, F., Liu, X., Mattes, T.E., Cupples, A.M., 2015. Elucidating carbon uptake from vinyl chloride using stable isotope probing and Illumina sequencing. Appl. Microbiol. Biotechnol. 99, 77357743. https://doi.org/10.1007/s00253-015-6606-1 
1195 Pérez-De-Mora, A., Zila, A., McMaster, M.L., Edwards, E. a., 2014. Bioremediation of chlorinated ethenes in fractured bedrock and associated changes in dechlorinating and nondechlorinating microbial populations. Environ. Sci. Technol. 48, 5770-5779. https://doi.org/10.1021/es404122y

Richards, P.M., Liang, Y., Johnson, R.L., Mattes, T.E., 2019. Cryogenic soil coring reveals coexistence of aerobic and anaerobic vinyl chloride degrading bacteria in a chlorinated ethene contaminated aquifer. Water Res. 157, 281-291. https://doi.org/10.1016/j.watres.2019.03.059

Ritalahti, K.M., Amos, B.K., Sung, Y., Wu, Q., Koenigsberg, S.S., Löffler, F.E., 2006. Quantitative 1203 PCR targeting 16S rRNA and reductive dehalogenase genes simultaneously monitors multiple Dehalococcoides strains. Appl. Environ. Microbiol. 72, 2765-2774. https://doi.org/10.1128/AEM.72.4.2765-2774.2006

Robertson, W.J., Bowman, J.P., Franzmann, P.D., Mee, B.J., 2001. Desulfosporosinus meridiei sp . nov ., a spore- forming sulfate-reducing bacterium isolated from gasolene-contaminated groundwater. Int. J. Syst. Evol. Microbiol. 51, 133-140.

Scheutz, C., Broholm, M.M., Durant, N.D., Weeth, E.B., Jørgensen, T.H., Dennis, P., Jacobsen, C.S., Cox, E.E., Chambon, J.C., Bjerg, P.L., 2010. Field evaluation of biological enhanced reductive dechlorination of chloroethenes in clayey till. Environ. Sci. Technol. 44, 5134-5141.

Schippers, A., Jorgensen, B.B., 2002. Biogeochemistry of pyrite and iron sulfide oxidation in https://doi.org/10.1021/es1003044 

community structures suggest Fe(III) and vinyl chloride reduction as antagonistic terminal electron-accepting processes. Environ. Sci. Technol. 47, 6836-6845. https://doi.org/10.1021/es304017s

Silverman, M.P., 1967. Mechanism of bacterial pyrite oxidation. J. Bacteriol. 94, 1046-1051.

Sleep, B.E., Brown, A.J., Lollar, B.S., 2005. Long-term tetrachlorethene degradation sustained by endogenous cell decay. J. Environ. Eng. Sci. 4, 11-17. https://doi.org/10.1139/s04-038

Smits, T.H.M., Assal, A., Hunkeler, D., Holliger, C., 2011. Anaerobic Degradation of Vinyl Chloride in Aquifer Microcosms. J. Environ. Qual. 40, 915. https://doi.org/10.2134/jeq2010.0403

Theis, C. V, 1935. The relation between the lowering of the Piezometric surface and the rate and duration of discharge of a well using groundwater storage. Trans. - Am. Geophys. Union 16, $519-524$.

Thullner, M., Centler, F., Richnow, H., Fischer, A., 2012. Organic Geochemistry Quantification of organic pollutant degradation in contaminated aquifers using compound specific stable isotope analysis - Review of recent developments. Org. Geochem. 42, 1440-1460. https://doi.org/10.1016/j.orggeochem.2011.10.011

Vanstone, N.A., Focht, R.M., Mabury, S.A., Sherwood Lollar, B., 2004. Effect of Iron Type on Kinetics and Carbon Isotopic Enrichment of Chlorinated Ethylenes during Abiotic Reduction on Fe(O). Ground Water. https://doi.org/10.1111/j.1745-6584.2004.tb02673.x

Wang, P.H., Correia, K., Ho, H.C., Venayak, N., Nemr, K., Flick, R., Mahadevan, R., Edwards, E.A., 2019. An interspecies malate-pyruvate shuttle reconciles redox imbalance in an anaerobic microbial community. ISME J. https://doi.org/10.1038/s41396-018-0333-4 
1239 Weber, K.A., Achenbach, L.A., Coates, J.D., 2006. Microorganisms pumping iron: Anaerobic 1240 microbial iron oxidation and reduction. Nat. Rev. Microbiol. 4, 752-764.

1242

1243

1244

1245

1246

1247

1248

1249

1250

1251

1252

1253

1254

1255

1256

1257

1258

1259

1260

Wiegert, C., Aeppli, C., Knowles, T., Holmstrand, H., Evershed, R., Pancost, R.D., Macháčková, J., Gustafsson, Ö., 2012. Dual Carbon-chlorine stable isotope investigation of sources and fate of chlorinated ethenes in contaminated groundwater. Environ. Sci. Technol. 46, 10918-10925. https://doi.org/10.1021/es3016843

Wiegert, C., Mandalakis, M., Knowles, T., Polymenakou, P.N., Aeppli, C., Macháčková, J., Holmstrand, H., Evershed, R.P., Pancost, R.D., Gustafsson, O., Gustafsson, Ö., 2013. Carbon and chlorine isotope fractionation during microbial degradation of tetra-and trichloroethene. Environ. Sci. Technol. 47, 6449-6456. https://doi.org/10.1021/es305236y

Wilson, J.T., 2010. Monitored natural attenuation of chlorinated solvent plumes, in: Stroo, H.F., Ward, C.H. (Eds.), In Situ Remediation of Chlorinated Solvent Plumes. Springer Science + Business Media, pp. 325-355.

Yang, Y., Higgins, S.A., Yan, J., Şimşir, B., Chourey, K., Iyer, R., Hettich, R.L., Baldwin, B., Ogles, D.M., Löffler, F.E., 2017. Grape pomace compost harbors organohalide-respiring Dehalogenimonas species with novel reductive dehalogenase genes. ISME J. 2767-2780. https://doi.org/10.1038/ismej.2017.127

Yargicoglu, E.N., Reddy, K.R., 2015. Review of biological diagnostic tools and their applications in geoenvironmental engineering. Rev. Environ. Sci. Bio/Technology 14, 161-194. https://doi.org/10.1007/s11157-014-9358-y

Yarza, P., Yilmaz, P., Pruesse, E., Glöckner, F.O., Ludwig, W., Schleifer, K.H., Whitman, W.B., 
1261 Euzéby, J., Amann, R., Rosselló-Móra, R., 2014. Uniting the classification of cultured and 1262 uncultured bacteria and archaea using 16S rRNA gene sequences. Nat. Rev. Microbiol. 12, 1263 635-645. https://doi.org/10.1038/nrmicro3330

1264 Zhang, J., Kobert, K., Flouri, T., Stamatakis, A., 2014. PEAR : a fast and accurate Illumina Paired1265 End reAd mergeR. Bioinformatics 30, 614-620. https://doi.org/10.1093/bioinformatics/btt593 1266 